https://creativecommons.org/licenses/by/4.0/

\title{
DESARROLLO DE UN SISTEMA DE GESTIÓN DE ALMACENAMIENTO PARA EMPRESAS PRODUCTORAS DE VINO (CASO-BODEGAS AÑEJAS LTDA) ${ }^{1}$
}

\author{
The development of a management storage system for wine \\ production companies (Caso - Bodegas Añejas Ltda)
}

GABRIEL ESTEBAN GONZÁLEZ ESPITIA², KIMBERLY ALAMET FARFÁN TRUJILLO3, EVER ÁNGEL FUENTES ROJAS ${ }^{4}$

Recibido: 27 de septiembre de 2018. Aceptado: 18 de octubre de 2018

DOI: http://dx.doi.org/10.21017/rimci.2019.v6.n11.a56

\begin{abstract}
Resumen
El sistema de gestión de almacenamiento busca el control de procesos logísticos en la operación como los de compras, servicio al cliente, gestión de inventarios, almacenamiento y transporte, para optimizar la cadena de suministro; sin embargo, varios estudios utilizan otras herramientas que pueden ser adecuadas según el sector de análisis. En el caso de Bodegas Añejas Ltda. se presentan tres alternativas que permiten el desarrollo del sistema de gestión de almacenamiento: El supply chain operations reference model, que permite buscar el desperdicio de espacios que afectan las condiciones del trabajador y cruces en el flujo operativo, lo que aumenta los tiempos en las actividades; el método Systematic layout planning que elimina movimientos innecesarios en la operación y por último una simulación en Flexsim donde se plantean dos propuestas para reconocer la viabilidad de los cambios, donde se logra incrementar en 2.108 botellas que representa un aumento de $\$ 17.000 .000$ en ventas mensuales.
\end{abstract}

Palabras clave: Gestión de almacenamiento, cadena de suministro, Flexsim, método SCOR, método SLP.

\begin{abstract}
The storage management system seeks to control logistics processes in the operation as those of purchases, service to the client, inventory management, storage and transport, to optimize the supply chain; however, several studies use other tools that may be according to the analysis sector. In the case of Bodegas Añejas Ltda. three alternatives were presented that allow the development of the storage management system: The supply chain operations reference model that allows to look for the waste of spaces that affect the conditions of the worker and crossings in the operative flow, which increases the times in the activities; the method systematic layout planning that eliminates unnecessary movements in the operation and finally a simulation in Flexsim where two proposals are proposed to recognize the viability of the changes, where it is possible to increase in 2,108 bottles representing an increase of $\$ 17,000,000$ in monthly sales.
\end{abstract}

Keywords:Storage management, supply chain, Flexsim, SCOR method, SLP method.

1 El artículo se deriva del proyecto Desarrollo de un sistema de gestión de almacenamiento en Bodegas Añejas Ltda., ejecutado entre enero de 2017 y marzo de 2018 desde el programa de Ingeniería industrial en la Universidad Libre sede Bogotá.

2 Ingeniería industrial, Estudiante de la Faculta de Ingeniería, Universidad Libre Bogotá - Colombia. ORCID: https://orcid.org/0000-00026988-1956 Correo electrónico: gabriele.gonzaleze@unilibrebog.edu.co

3 Ingeniería industrial, Estudiante de la Facultad de Ingeniería, Universidad Libre Bogotá - Colombia. ORCID: https://orcid.org/0000-00019394-784X. Correo electrónico: kimberlya.farfant@unilibrebog.edu.co

4 MBA., profesor de la Facultad de Ingeniería, Universidad Libre Bogotá - Colombia. ID: https://orcid.org/0000-0001-9671-5884 Correo Electrónico: ever.fuentes@unilibre.edu.co 


\section{INTRODUCCIÓN}

B odegas Añejas LtDa., es una empresa colombiana con NIT 860000157-8, fundada el 18 de octubre de 1939, siendo la primera planta de vinos diseñada y construida por ciudadanos españoles que se dedica al desarrollo, producción y comercialización a nivel nacional de licores; la sede principal se encuentra en la ciudad de Bogotá D.C. y cuenta con sucursales alternas en Ibagué, Villavicencio, Cali y Medellín.

Esta se ha caracterizado por haber sido pionera en esta industria del mercado de licores por su gran variedad de productos, ofreciendo desde vinos de alta calidad hasta cremas de licor; de igual modo su productividad y satisfacción al cliente han logrado el posicionamiento de su marca y fidelización de sus consumidores, por más de siete décadas [1]; para dar mejoría a estos factores es necesario tener un control de la mercancía almacenada y una gestión de inventario, siendo este una parte esencial de la infraestructura de cualquier organización, con el objetivo de aumentar las utilidades. La compañía maneja un sistema de información del proceso de almacenamiento manual y desde el 2015 empezaron a utilizar el Excel, sin embargo, este cambio de método ha ocasionado actualmente equivocaciones en el control de inven- tario y almacenamiento de productos, lo que genera un incumplimiento a los clientes. En la fig. 1 se encuentran las causas críticas destacadas en el proceso de la empresa, que generan un sistema inadecuado de almacenamiento.

La gerencia, siendo consiente del impacto negativo del proceso de almacenamiento actual, autoriza la realización del proyecto "desarrollo de un Sistema de gestión de almacén en Bodegas Añejas Ltda.", para el mejoramiento del control y sistematización de su cadena de suministro, incrementando la eficiencia y eficacia en el manejo de la bodega.

El contenido del artículo comprende cuatro secciones: la primera presenta proyectos realizados sobre un sistema de gestión de almacenamiento o temas similares con el fin de tener una orientación de una metodología y se exponen fundamentos teóricos y conceptuales que soportan el desarrollo del trabajo; la segunda sección describe en detalle la metodología aplicada para la recopilación y análisis de información, los métodos utilizados para generar la mejor solución a la problemática presentada en la bodega (Ver fig. 2), donde el modelo SCOR (Supply Chain Operations Reference model, modelo de referencia de operaciones de la cadena de suministro) determina las desconexiones
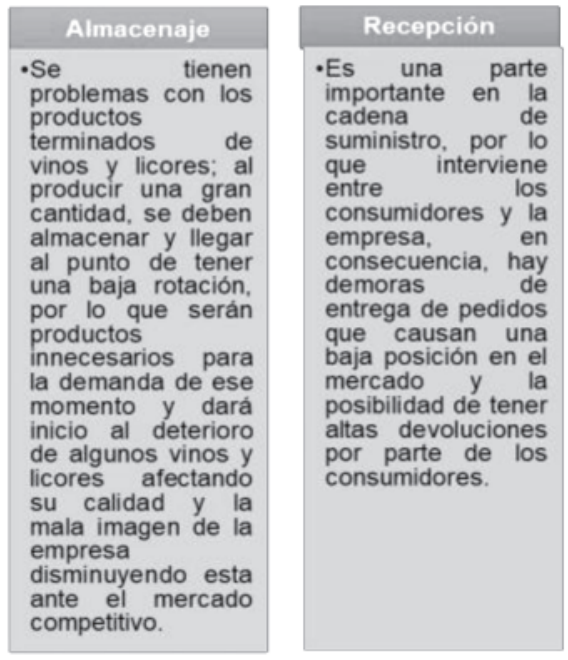

\section{Clientes}

- Van de la mano con la recepción, ya que, si esta no tiene una implementación del proceso logístico. comienza a afectar las entregas, la insatisfacción del cliente, y así mismo el descenso de esta empresa. Por lo que los clientes ayudan a mejor la cadena de suministro con sus quejas, inquietudes y sugerencias.

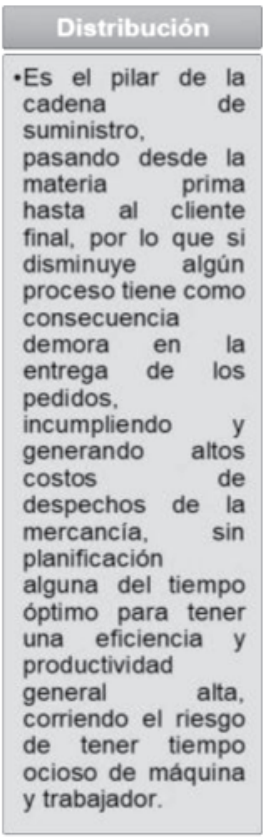

Fig. 1. Causas críticas. Fuente: Los autores. 
de la cadena de suministro y proponer buenas prácticas. Posteriormente en esta misma sección se evalúan los mecanismos utilizados para el manejo de materiales como punto de partida para el desarrollo de la metodología SPL (Systematic Layout Planning, planificación sistemática del diseño) con lo que se busca establecer la mejor ubicación de los productos para satisfacer las necesidades de los clientes. Finalmente, en la tercera parte se discuten los resultados obtenidos y se valida el sistema de gestión de almacenamiento por medio de una simulación en el software Flexsim 6.6.2 que facilita la interacción de las variables en diferentes escenarios a partir de estrategias que mejoran la toma decisiones de la organización y finalmente, la sección cuatro presenta la conclusión que se desprenden de esta investigación.

\section{Marco Teórico}

Antecedentes: En la tabla I se mencionan distintas metodologías de proyectos similares donde se utilizan softwares, modelos, control de inventarios, distribución de planta e indicadores con respecto a la oferta de cada empresa, con el fin de tener una guía para el desarrollo de este. (Ver tabla I).

Para el sistema de almacenamiento propuesto en este artículo se evalúo cinco metodologías realizadas por los autores nombrados en la tabla anterior, donde se escoge usar el método $\mathrm{ABC}$ para conocer el flujo de los productos y se revisa los diferentes softwares para la simulación de nuestro proyecto.

A continuación, se presentan los principales conceptos para tener en cuenta, cuando se desarrolla un sistema de gestión de almacenamiento:

- Clasificación ABC: Consiste en efectuar un análisis de los inventarios estableciendo capas de inversión o categorías con objeto de lograr un mayor control y atención sobre los inventarios, que por su número y monto merecen una vigilancia y atención permanente [7]. El análisis de los inventarios es necesario para establecer tres (03) grupos de productos y generalmente el $80 \%$ del valor del inventario está representado por el $20 \%$ de los artículos y el $80 \%$ de los artículos representan el $20 \%$ de la inversión:

- Almacenamiento: se define como una parte de la logística que incluye las actividades relacionadas con el almacén; en concreto, guardar y custodiar existencias que no están en proceso de fabricación, ni de transporte, permite acercar las mercaderías a los puntos de consumo [8].

- Almacén: es una unidad de servicio en la estructura orgánica y funcional de una empresa comercial o industrial, con objetivos

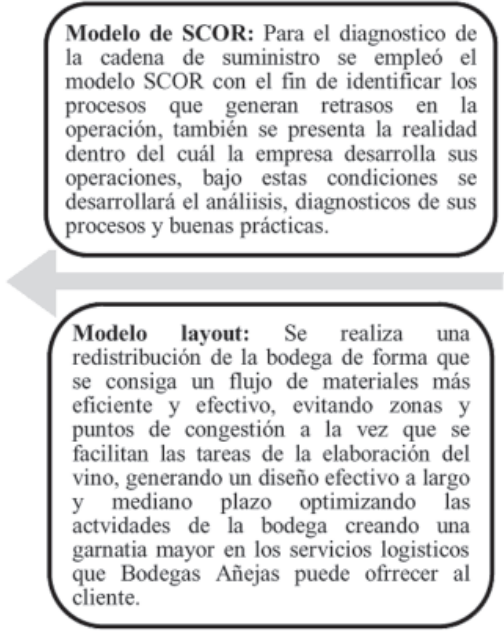

Clasificación ABC: Permitió la identificación de los productos que tienen un impacto importante en el mercado generando altas ganancias; los cuales se dividen en tres categorias de productos que necesitarán modos dde control distintos.

Simulación con el software Flexsim permitio conocer y estudiar un mejor entendimiento del sistema y por consiguiente a sugeriri estrategias que mejores la operación y eficiencia de os sistemas propuestos a Bodegas Añejas Ltda.

Fig. 2. Métodos utilizados. Fuente: Los autores. 
Tabla I. Antecedentes.

\begin{tabular}{|c|c|c|c|}
\hline Nombre del proyecto & Autores & Año y país & Resumen \\
\hline $\begin{array}{l}\text { Modelo de simulación del } \\
\text { proceso de almacenamiento y } \\
\text { distribución en la bodega de la } \\
\text { distribuidora de papel de la } \\
\text { empresa Muebles \& } \\
\text { Accesorios S.A para el } \\
\text { mejoramiento de su sistema }\end{array}$ & $\begin{array}{l}\text { Edgar Alberto Peña } \\
\text { Guerrero, Esmeralda } \\
\text { Forero Forero }\end{array}$ & $\begin{array}{c}\text { 2012, } \\
\text { Colombia }\end{array}$ & $\begin{array}{l}\text { Se propone un sistema de inventarios } \\
\text { basados en técnicas de simulación donde se } \\
\text { desarrolla diferentes actividades como la } \\
\text { construcción de redes de proceso, evaluación } \\
\text { de la forma actual de manejo de inventarios } \\
\text { y simulación actual y propuesta en } \\
\text { PROMODEL donde se muestra que se puede } \\
\text { reducir los costos de mantener y de pedidos, } \\
\text { por otra parte, se evidencia una reducción de } \\
\$ 65.885 .000 \text { anuales frente a los costos totales, } \\
\text { mejorando el nivel de inventarios y teniendo } \\
\text { presente la demanda por año para no } \\
\text { generar faltante }\end{array}$ \\
\hline $\begin{array}{l}\text { Diseño de un modelo de } \\
\text { almacenamiento y distribución } \\
\text { de equipos y materiales en la } \\
\text { bodega de } \\
\text { SAEXPLORATION- } \\
\text { SUCURSAL Colombia }\end{array}$ & $\begin{array}{l}\text { Leidy Johanna } \\
\text { González Guevara }\end{array}$ & $\begin{array}{c}\text { 2015, } \\
\text { Colombia }\end{array}$ & $\begin{array}{l}\text { Cuyo objetivo es diseñar un Layout para } \\
\text { mejorar su proceso de almacenamiento y } \\
\text { distribución con el método ABC para dar } \\
\text { soluciones en el desarrollo de cada uno de } \\
\text { los procesos involucrados en la cadena de } \\
\text { abastecimiento optimizando los costos y } \\
\text { tiempos }\end{array}$ \\
\hline $\begin{array}{l}\text { Propuesta de mejoramiento de } \\
\text { la cadena de abastecimiento } \\
\text { enfocada en la gestión de } \\
\text { inventarios, procesos de } \\
\text { almacenamiento y preparación } \\
\text { de pedidos en el cedi de } \\
\text { COLNOTEX S.A. }\end{array}$ & $\begin{array}{l}\text { Lina María Miranda } \\
\text { Fernández y Andrea } \\
\text { Villamizar Castro }\end{array}$ & $\begin{array}{c}2013, \\
\text { Colombia }\end{array}$ & $\begin{array}{l}\text { Donde se diseña una propuesta de } \\
\text { mejoramiento de la cadena de } \\
\text { abastecimiento enfocada en el proceso de } \\
\text { almacenamiento, donde se utiliza un método } \\
\text { de programa WINQSB con el cual se } \\
\text { mejorará un } 28,6 \% \text { la productividad que se } \\
\text { traduce financieramente en una rentabilidad } \\
\text { del } 31,3 \% \text { la cual es mayor a la tasa de } \\
\text { oportunidad de la empresa }\end{array}$ \\
\hline $\begin{array}{l}\text { Propuesta de mejoramiento } \\
\text { del sistema de abastecimiento } \\
\text { y almacenamiento del a } \\
\text { empresa PLASTIFERGO }\end{array}$ & $\begin{array}{c}\text { Nathalia Chaparro } \\
\text { Sierra }\end{array}$ & $\begin{array}{c}\text { 2013, } \\
\text { Colombia }\end{array}$ & $\begin{array}{l}\text { Diseñan el sistema de abastecimiento y } \\
\text { almacenaje utilizando el método ABC } \\
\text { realizando una disminución } \$ 4.486 .801 \text { en el } \\
\text { costo total de los inventarios y también } \\
\text { disminuyendo el costo de poner una orden } \\
\text { de pedido al proveedor en } \$ 12.491 \text { y así } \\
\text { logrando un alto benefició representado una } \\
\text { tasa interna de retorno del } 56 \%\end{array}$ \\
\hline $\begin{array}{l}\text { Diseño de Sistema de Gestión } \\
\text { de Almacén para la mejora del } \\
\text { control de la información de la } \\
\text { Empresa Vitivinícola Bodega } \\
\text { Bailetti Chincha }\end{array}$ & $\begin{array}{l}\text { Huamán Atúncar } \\
\text { Fernando Sobrino } \\
\text { Mejía Pablo }\end{array}$ & $\begin{array}{l}\text { 2012, Chincha } \\
\text { Perú }\end{array}$ & $\begin{array}{l}\text { Se determina la contribución del sistema } \\
\text { para la mejora del almacén y su contribución } \\
\text { en el proceso de pedidos de producción } \\
\text { donde se utilizó las herramientas de visual } \\
\text { studio 2008, SQL server } 2009 \text { y Rational Rose } \\
\text { para la administración del almacén }\end{array}$ \\
\hline
\end{tabular}

Furente: Los autores a partir de [2]; \{3\}; \{4\}; \{5\}; f6\}. --.

bien definidos de resguardo, custodia, control y abastecimiento de materiales (materias primas) o productos terminados [9]. Por lo tanto, el almacenamiento o resguardo de los materiales ha de ser ordenado y con las condiciones más favorables que ayuden a la consecución de los objetivos de la empresa. Así, al comprar y guardar materiales en almacén se debe estar consciente de que es exactamente lo mismo que depositar dinero en un banco, pues su finalidad es protegerlos, generar utilidades y administrarlos correctamente. La fórmula de oro de una empresa que se dedica a la comercialización de productos terminados consiste en comprar y exhibir el mayor número de productos y desplazarlos antes de la fecha límite de pago convenido [10]. 
- Almacén Cubierto: es el que ofrece mayor protección a los elementos y materiales que allí se almacenan, ya que es posible controlar diversas variables tales como humedad, temperatura, iluminación y muchas otras que influyen directamente en la preservación y vida útil de los productos [11].

- Almacenamiento en bloque: También llamado Almacén Compacto, se basa principalmente en el apilamiento de mercancía una sobre otra, directamente desde el suelo, en forma de bloques compactos en el almacén [12]. En este tipo de almacenaje se debe tomar en cuenta la resistencia de la base y la estabilidad de la columna. Es utilizado para colocar el producto terminado en cajas y trasladarlo a la estantería de almacenamiento [13].

- Almacén convencional: Es aquel cuyo equipamiento máximo de almacenaje consiste en estanterías para el depósito de paletas, con carretillas de mástil retráctil. Esto influirá en las dimensiones del almacén, cuya altura oscila entre 6 y $7 \mathrm{~m}$. Además, deberá tener pasillos anchos para que discurran sin dificultad las carretillas [14].

- Estantería: mueble con estantes horizontales que sirven para almacenar distintos tipos y formas de carga en estantes y estructuras alveolares de altura variable, sirviéndose para ello de equipos de manutención manual o mecánica [15]. Así mismo, la estantería es un sistema de almacenaje muy extendido con estructura metálica compuesta por puntales fijados al suelo y arriostrados entre sí formando escalas y por largueros horizontales que conforman niveles de carga, su montaje es relativamente sencillo, disponen de una capacidad de carga muy considerable en cuanto a peso y volumen, optimizan el espacio disponible, especialmente la altura de almacenamiento [16] (Ver Fig. 3).

- Sistema de almacenamiento: es prever el espacio y el equipo necesarios para almacenar y proteger los artículos hasta que se utilicen o embarquen, de tal manera que resulte más económica en cuanto a costos, proporcionando las instalaciones, el equipo, el personal, y las técnicas necesarias para recibir y almace-

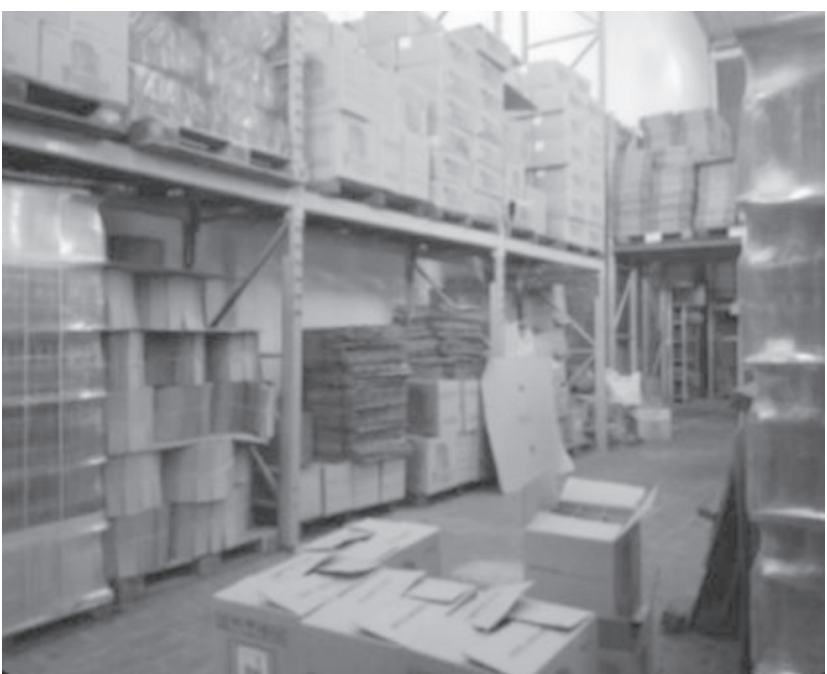

Fig. 3. Estantería estática.

Fuente: Tomado por los autores en Bodegas Añejas Ltda.

nar materia prima, productos en proceso y productos terminados [17], y en términos de sistemas de almacenamiento existen distintas posibilidades, según las características de los materiales que van a ser almacenados, el espacio con que se cuente (y que ahora pasa a ser una restricción) y la necesidad de fluidez (nivel de servicio) del almacén [18]. La ubicación física de los materiales en los almacenes debe ser establecida de manera que permita la localización rápida y sin errores de las unidades.

El sistema de almacenamiento convencional es el más universal para el acceso directo y unitario a cada paleta [19]. Este es industrial por excelencia y consiste en almacenar las unidades combinando mercancías paletizadas con artículos individuales. Los niveles altos se pueden destinar para el almacenamiento de paletas completas y los más bajos para la preparación manual de expediciones o picking.

Sistema de almacenamiento semiautomático - automático: Están diseñados para ser operados a través de transelevadores para paletas de forma automática utilizando equipos robotizados para la manipulación de la carga, aptos para almacenar paletas o cajas.

- Codificación de productos: es un conjunto de números o números y letras que se asig- 
na a cada producto, bulto o unidad de carga para su identificación [20]. Para facilitar la administración de los materiales se deben clasificar los artículos con base en un sistema justo, que permita procedimientos de almacenajes adecuados, operativos de la bodega y control eficiente de las existencias. Se da el nombre de clasificación de artículos a la catalogación, simplificación, especificación, normalización, esquematización y codificación de todos los materiales que componen las existencias de la empresa [21].

Definición de cada una de sus etapas [22]: (Ver Fig. 4)

- Flujo logístico: es el proceso donde se gestiona estratégicamente el movimiento y almacenaje de las materias primas, productos terminados y entrega del producto donde se debe tener en cuenta la cantidad correcta, producto de buena calidad y el plazo preciso para entregarlo [23].

- Método SCOR (Supply chain operations reference model): Es una herramienta de gestión estratégica para tener una visión global de toda la cadena de suministro; especifica cada uno de los procesos y elementos, analiza, mide, establece objetivos de rendimiento, determina oportunidades de mejora, identifica las mejores prácticas y prioriza proyectos de mejoramiento para garantizar el cumplimiento de la promesa de servicio a través de la red de distribución del sistema [24].

En la Tabla II se menciona específicamente lo que contiene el método:

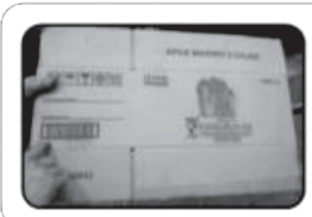

\section{Catalogación}

Significa inventario de todos los artículos los existentes sin omitir ninguna, permite la presentación conjunta de todo el artículo proporcionando una idea general de la colección.

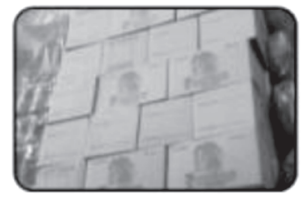

Simplificación

Reducción de la gran diversidad de artículos empleados con una misma finalidad, cuando existen dos o más piezas para un mismo fin, se recomienda la simplificación favorece la normalización.

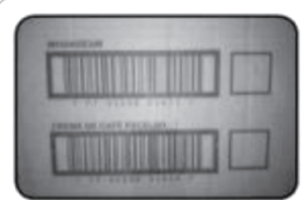

\section{Especificación}

Descripción detallada de un artículo, como sus medidas, formato, tamaño, peso, etc. Cuando mayor es la especificación, se contará con más informaciones sobre el artículo y menos dudas con respecto de su composición y caracteristicas. La especificación facilita las compras del artículo, pues permite dar al proveedor una idea precisa del material que se comprara.

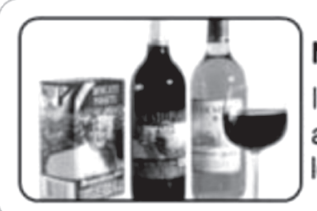

Normalización

Indica la manera en que el material debe ser utilizado en sus diversas aplicaciones. La palabra deriva de normas, que son las recetas sobre el uso de los materiales.

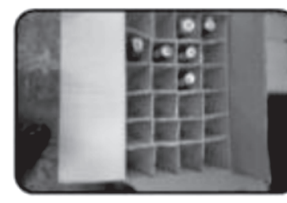

Estandarización

Significa establecer idénticos estándares de peso, medidas y formatos para los materiales de modo que no existan muchas variaciones entre ellos, haciendo que, por ejemplo, los tornillos sean de tal o cual especificación, con lo cual se evita que cientos de tornillos diferentes entre innecesariamente en existencias.

Fig. 4. Etapas para codificación. Fuente: Los autores a partir de Martínez, Burgeño y Castelo, [22]. 
Tabla II. Contenido del modelo SCOR.

\begin{tabular}{|l|l|l|}
\hline \multicolumn{1}{|c|}{ Etapas } & \multicolumn{1}{c|}{ Estructura } & \multicolumn{1}{c|}{ Diagramas } \\
\hline $\begin{array}{l}\text { Definición y evaluación del } \\
\text { alcance y de los procesos } \\
\text { básicos de la cadena de } \\
\text { suministro }\end{array}$ & $\begin{array}{l}\text { Nivel superior: Tipos de } \\
\text { procesos }\end{array}$ & $\begin{array}{l}\text { Diagrama de ámbito de aplicación o alcance del negocio. } \\
\text { Establece el alcance de un proyecto u organización }\end{array}$ \\
\hline $\begin{array}{l}\text { Definición y evaluación de las } \\
\text { categorías de procesos. }\end{array}$ & $\begin{array}{l}\text { Nivel de configuración: } \\
\text { Categorías de procesos }\end{array}$ & $\begin{array}{l}\text { Mapa Geográfico. Describe los flujos de materiales en el } \\
\text { contexto geográfico, o sea, dentro de los nodos de una SC: } \\
\text { almacenes, fábricas, centros de distribución (CD) o tiendas }\end{array}$ \\
\hline $\begin{array}{l}\text { Definición de los elementos de } \\
\text { proceso o descomposición de } \\
\text { procesos. }\end{array}$ & $\begin{array}{l}\text { Nivel de elementos del } \\
\text { proceso: Descomposición } \\
\text { de procesos - actividades }\end{array}$ & $\begin{array}{l}\text { Diagrama de hilos o diagrama de flujo de materiales. Está } \\
\text { enfocado a las categorías de proceso, para describir el alto } \\
\text { nivel de complejidad o redundancia }\end{array}$ \\
\hline $\begin{array}{l}\text { Implementación de los } \\
\text { cambios de la cadena de } \\
\text { suministro }\end{array}$ & $\begin{array}{l}\text { Nivel implementación: } \\
\text { Tareas y practicas } \\
\text { especificas }\end{array}$ & $\begin{array}{l}\text { Diagramas de proceso o diagrama de flujo de trabajo. } \\
\text { Describe información de materiales y flujo de trabajo; en el } \\
\text { diagrama se destaca información sobre las personas e } \\
\text { interacciones en el sistema }\end{array}$ \\
\hline
\end{tabular}

Fuente: Los autores información suministrada de de Prakash, et al. [25].

- Modelo SLP (Systematic Layout Planning) de Muther: Fue diseñado como una guía para el planeamiento de distribución en planta publicado en 1968, aunque creado para aplicar en cualquier uso se ha abordado con más fuerza para el área industrial, dada la complejidad que se asume y que el SLP facilita, en palabras del Muther (1968) " permite identificar, valorar y visualizar todos los elementos involucrados en la implantación y las relaciones existentes entre ellos".

Este modelo cuenta con cuatro fases o niveles de la distribución en planta que se deben producir en secuencia para así obtener los mejores resultados, los cuales son: (Ver Tabla III).

\section{Metodología}

Diseño Metodológico: Se aplica un tipo de investigación descriptivo y explicativo con un enfoque cuantitativo ya que los estudios cuantitativos tienden a ser altamente estructurados [27], de modo que el investigador especifica las características principales del diseño antes de obtener un solo dato; de tal modo que se obtuvo datos precisos que permitieron el adecuado proceso de investigación, las mediciones, el análisis de los datos estadísticos y de las variables que definen el tipo de problema a solucionar.

El propósito de estas metodologías es poder simultáneamente recolectar, procesar y analizar la información obtenida, ya que mediante los datos

Tabla III. Etapas del modelo SLP.

\begin{tabular}{|ll|l|}
\hline \multicolumn{2}{|c|}{ Etapa } & \multicolumn{1}{c|}{ Definición } \\
\hline 1. & Localización & $\begin{array}{l}\text { Decidirse la ubicación de la planta a distribuir. En caso de una redistribución el objetivo será determinar } \\
\text { si la planta se mantendrá en el emplazamiento actual o si se trasladará hacia un edificio nuevo o bien } \\
\text { hacia un área de similares características y potencialmente disponible }\end{array}$ \\
\hline $\begin{array}{l}\text { 2. } \\
\begin{array}{l}\text { Plan de } \\
\text { distribución } \\
\text { general }\end{array}\end{array}$ & $\begin{array}{l}\text { Establecer el patrón de flujo para el total de áreas que deben ser atendidas en la actividad a desarrollar, } \\
\text { indicando también (y para cada una de ellas) la superficie requerida, la relación entre las diferentes } \\
\text { áreas y la configuración de cada actividad principal, departamento o área, sin atender aún las cuestiones } \\
\text { referentes a la distribución en detalle. El resultado de esta fase nos llevará a obtener un bosquejo o } \\
\text { diagrama a escala de la futura planta }\end{array}$ \\
\hline 3. & $\begin{array}{l}\text { Plan de } \\
\text { distribución } \\
\text { detallada }\end{array}$ & $\begin{array}{l}\text { Estudiar y preparar en detalle el plan de distribución alcanzado en el punto anterior e incluye el análisis, } \\
\text { definición y planificación de los lugares donde van a ser instalados/colocados los puestos de trabajo, así } \\
\text { como la maquinaria o los equipos e instalaciones de la actividad. }\end{array}$ \\
\hline 4. & Instalación & $\begin{array}{l}\text { Realizar los movimientos físicos y ajustes necesarios, conforme se van instalando los equipos, máquinas } \\
\text { e instalaciones, para lograr la materialización de la distribución en detalle que fue planeada. }\end{array}$ \\
\hline
\end{tabular}

Fuente: Los autores información suministrada de Quintana y Rangel [26] 
cuantitativos se tendrá un análisis de las áreas más críticas, para lograr tener un control sobre ellas, por lo cual, las herramientas que se van a usar son estadísticas y probabilística [28].

El proceso metodológico para el desarrollo del sistema de gestión de almacenamiento se realizó en cuatro momentos, de los cuales la información $\mathrm{y}$, datos suministrados y obtenidos son revisados y aprobados por la gerencia general de Bodegas Añejas Ltda.; en el primer momento se realiza el diagnostico donde se utiliza el modelo SCOR. para reconocer los problemas presentados en la compañía realizando diagramas de flujo, procesos, estandarización de tiempos por actividades y la cadena de suministro; para el segundo momento se realiza el método $\mathrm{ABC}$ que analiza las rotaciones de los productos y su utilidad durante el año usando una base de datos de 2 años para su análisis; el tercer momento se realiza el SLP. donde se mapea toda la bodega y se construye el diseño por la herramienta SKETCHUP., además se realiza el plano del Layout para tener en cuenta las medias correspondientes de los procesos por medio de Visio y se desarrolla 2 propuestas que optimizan las actividades para la compañía, y por último, se muestra la viabilidad de los diseños nuevos expuestos mediante el software Flexsim donde nos concluye un porcentaje de crecimiento y una mejora en las actividades.

\section{Resultados}

El desarrollo del sistema de gestión de almacenamiento en Bodegas Añejas Ltda. tiene como primer momento la recolección de información sobre el proceso de almacenamiento, realizando las siguientes actividades del modelo Supply Chain Operations Reference (SCOR):

Estudio de tiempos y movimiento: Se realiza para la producción de vinos con el fin de identificar los elementos que intervienen, los que no generan valor y la estandarización de los tiempos. Se utiliza un cronómetro, se determinan 6 ciclos y en cada uno se realizan 2 tomas de tiempos, una en la mañana y una en la tarde en la jornada laboral. Las operaciones del proceso productivo son: Recepción, estrujado del mosto, fermentación, clarificación, trasiego, filtración, ensamblaje, añejamiento, embotellado, empacado y almacenamiento.
Se calculan los suplementos tomando como referencia la Organización Internacional del Trabajo (OIT) y el análisis de las necesidades de los trabajadores de la empresa. Para las mujeres se estableció un suplemento del $21 \%$ y para hombres del $16 \%$. De las 41 actividades del proceso 12 son realizadas por mujeres y 29 por hombres. En la Tabla IV, se observan los tiempos estandarizados.

Posteriormente se realiza un diagrama de flujo de procesos describiendo las actividades implicadas en el proceso de elaboración del vino, facilitando la compresión de los movimientos y sus relaciones para deducir posibles falencias durante este. (Ver Tabla V)

La Fig. 3 afirma que se tiene 32 operaciones, 6 transportes con un promedio de 867 segundos, se inspecciona cuatro veces, dos procesos de espera (Fermentación y filtración) que tienen en promedio una duración de un día y medio y dos almacenes, el de materia prima (Mosto) y producto terminado.

El proceso de elaboración de un vino comienza con el alistamiento del líquido de bayas, (Materia prima) donde se prepara para la fermentación, en una de las 35 barricas, para convertir las uvas en alcohol etílico (Duración entre 12 - 15 días, dependiendo de las temperaturas del día); posteriormente se realiza el trasiego, proceso en el cual se separa el vino de sustancias sólidas (Levadura) acumuladas en el fondo de los depósitos; luego se procede a la clarificación, donde se añade a la mezcla una sustancia que permita decantar (Eliminar partículas en suspensión) con la finalidad de pasar el vino perfectamente limpio de sedimentos; y por último, se hace el proceso de embotellamiento el cual se introduce el vino dentro de la botella, el sellado, etiquetado y empacado en cajas de 12-24 unidades e individual para su liberación al consumidor.

Por otro lado, se realiza un diagrama de hilo para describir el proceso existente, identificando fuentes, centros de distribución, proveedores y clientes con el fin de contemplar el flujo de material y su localización, en la Fig. 5 se presenta el mapa geográfico donde se ubican los proveedores de Bodegas Añejas Ltda.; las flechas negras representan el flujo de materia prima. En la Fig. 6 se muestran las localizaciones de los clientes a nivel nacional, las rutas del producto terminado y de 
Tabla IV. Promedio de estudio de tiempos y movimientos Bodegas Añejas Ltda.

\begin{tabular}{|c|c|c|c|c|c|c|c|c|c|}
\hline \multicolumn{7}{|c|}{ PROMEDIO DE TIEMPO Y MOVIMIENTO } & \multicolumn{3}{|c|}{$12 \frac{1}{2}$} \\
\hline \multicolumn{2}{|c|}{ Departamento:Producción } & \multicolumn{3}{|c|}{ Sección: Producción } & \\
\hline \multirow{2}{*}{\multicolumn{2}{|c|}{$\begin{array}{l}\text { Operación: Producción de vino } \\
\text { Herramientas: Moto bomba, montacarga , barriles, botellas y cajas } \\
\text { Producto: Vino } \\
\text { Material: Mosto } \\
\text { Observado por: Gabriel Gonzálezy Kimberiy Farfán }\end{array}$}} & \multirow{2}{*}{\multicolumn{3}{|c|}{$\begin{array}{l}\text { Estudio de métodos núm: } 1 \\
\text { Núm: } 1 \\
\text { Condiciones de trabajo: Normales } \\
\text { Comprobado: Claudia Archila }\end{array}$}} & \multicolumn{5}{|c|}{ Suplementos } \\
\hline & & & & & Mujer & $21 \%$ & & Homore & $16 \%$ \\
\hline & & \multicolumn{6}{|c|}{ 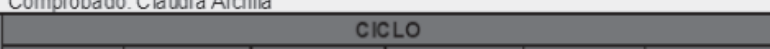 } & \multirow{2}{*}{ TOTAL } & \multirow{2}{*}{ PROMEDIO } \\
\hline Num. & Descripcion del proceso & 1 & 2 & 3 & 4 & 5 & 6 & & \\
\hline 1 & Descarga del mosto(barril) & 690,2 & 759,2 & 761,5 & 792,0 & 790,9 & 822,5 & 4616,3 & 769,4 \\
\hline 2 & Inspección de los barriles & 87,8 & 96,6 & 96,7 & 100,5 & 94,6 & 82,0 & 558,2 & 93,0 \\
\hline 3 & Transportar los barriles a la zona de producción & 795,6 & 875,2 & 939,7 & 977,3 & 944,5 & 818.6 & 5350.9 & 891.8 \\
\hline 4 & Jefe de bodega firma el documento & 14,6 & 16,1 & 16,6 & 17,3 & 17,3 & 15,0 & 97,0 & 16.2 \\
\hline 5 & Desinfectar la motobomba y manguera & 1714,1 & 1885,5 & 2785,3 & 2896,7 & 2654,3 & 2300,4 & 14236,4 & 2372,7 \\
\hline 6 & Transportar la motobomba a la zona de producción & 109,1 & 120,1 & 120,6 & 125,4 & 120,4 & 104,3 & 699.8 & 116,6 \\
\hline 7 & Instalación de la motobomba & 90,7 & 99,8 & 96,5 & 100,4 & 98,7 & 85,6 & 571,7 & 95,3 \\
\hline 8 & Encender la motobomba & 19,7 & 21,7 & 21,8 & 22,7 & 22,3 & 19,3 & 127,5 & 21,2 \\
\hline 9 & Apagar la motobomba y se desconecta la manguera & 23,1 & 25,4 & 24,4 & 25,4 & 24,6 & 21,3 & 144,1 & 24,0 \\
\hline 10 & Agregar los primeros insumos y se deja reposar & 1167,1 & 1283,8 & 1215,7 & 1264,3 & 1200,4 & 1040,4 & 7171,7 & 1195,3 \\
\hline 11 & $\begin{array}{l}\text { Instalación de la motobomba del barril de producción al } \\
\text { barril de fermentación }\end{array}$ & 314,8 & 346,3 & 320,6 & 333,4 & 321,2 & 278,4 & 1914,7 & 319,1 \\
\hline 12 & Apagar la motobomba y se desconecta la manguera & 31,3 & 34,5 & 30,7 & 31,9 & 31,4 & 27,2 & 187,0 & 31,2 \\
\hline 13 & Agregar segundos insumos & 115,8 & 127,4 & 163,1 & 169,6 & 154,3 & 133,7 & 863,9 & 144,0 \\
\hline 14 & Agitar la mescla del barril de fermentación & 728,7 & 801,6 & 471,8 & 490,7 & 537,9 & 466,1 & 3496,7 & 582.8 \\
\hline 15 & Fermentar & 1296000,0 & 1296000,0 & 1296000,0 & 1296000,0 & 1296000,0 & 1296000,0 & 7776000,0 & 1296000,0 \\
\hline 16 & Agregar tercer insumo & 98,9 & 108,8 & 110,5 & 114,9 & 109,4 & 94,8 & 637,4 & 106,2 \\
\hline 17 & Clarificación & 691200,0 & 691200,0 & 691200,0 & 691200,0 & 691200,0 & 691200,0 & 4147200,0 & 691200,0 \\
\hline 18 & Desiffectar la motobomba y manguera & 1700,3 & 1870,3 & 1974,8 & 2053,8 & 1951,5 & 1691,3 & 11242,1 & 1873,7 \\
\hline 19 & $\begin{array}{l}\text { Conectar la moto bomba del barril de fermentación al barril } \\
\text { de trasiego }\end{array}$ & 341,6 & 375,8 & 361,6 & 376,1 & 367,6 & 318,6 & 2141,4 & 356,9 \\
\hline 20 & Apagar la motobomba y se desconecta la manguera & 22,7 & 25,0 & 24,0 & 24,9 & 23,5 & 20,3 & 140,3 & 23,4 \\
\hline 21 & Desinfectar la maquina de filtración & 1987,1 & 2185,8 & 1564,1 & 1626,6 & 1801,2 & 1561,0 & 10725,8 & 1787,6 \\
\hline 22 & $\begin{array}{l}\text { Conectar la manguera del barril de trasiego a la maquina de } \\
\text { filtración }\end{array}$ & 101,4 & 111,5 & 106,4 & 110,7 & 109,1 & 94,6 & 633,6 & 105,6 \\
\hline 23 & Filtración 1 al barril de trasiego & 129600,0 & 129600,0 & 129600,0 & 129600,0 & 129600,0 & 129600,0 & 777600,0 & 129600,0 \\
\hline 24 & Filtración 2 al barrilde trasiego & 108000.0 & 108000,0 & 108000,0 & 108000,0 & 108000,0 & 108000,0 & 648000,0 & 108000,0 \\
\hline 25 & Filtración 3 al barrilde trasiego & 86400,0 & 86400,0 & 86400,0 & 86400,0 & 86400,0 & 86400,0 & 518400,0 & 86400,0 \\
\hline 26 & Tomar una mue stra de la mezcla & 91,7 & 76,1 & 77,3 & 80,4 & 75,0 & 65,0 & 465,5 & 77,6 \\
\hline 27 & Llevar una mezcla al laboratorio para analizar & 8550,8 & 7097,1 & 7414,1 & 7710,7 & 6996,7 & 6063,8 & 43833,2 & 7305,5 \\
\hline 28 & Pasar del barriltrasiego al barrilde envase & 4106,4 & 3408,3 & 3622,6 & 3767,5 & 3464,2 & 3002,3 & 21371,4 & 3561,9 \\
\hline 29 & Trasladar botellas a la zona de envase & 236,3 & 259,9 & 220,5 & 229,3 & 237,1 & 205,5 & 1388.4 & 231,4 \\
\hline 30 & Colocar las botellas en la maquina de lavar & 244,1 & 268,5 & 264,7 & 275,3 & 261,1 & 226,3 & 1540,0 & 256,7 \\
\hline 31 & Lavar botellas & 196,9 & 216,6 & 191,5 & 199,1 & 200,1 & 173,5 & 1177,7 & 196,3 \\
\hline 32 & Se pasa las botellas a la linea de producción & 58,5 & 64,4 & 68,7 & 71,4 & 69,6 & 60,3 & 392,9 & 65,5 \\
\hline 33 & Llenar las botellas & 109,8 & 120,8 & 117,8 & 122,5 & 120,1 & 104,1 & 695,0 & 115,8 \\
\hline 34 & Revisar la botella & 8,2 & 9.0 & 8,6 & 8,9 & 8,6 & 7,4 & 50,8 & 8.5 \\
\hline 35 & Colocar tapa a la botella & 63,3 & 69,7 & 67,1 & 69,8 & 69,0 & 59,8 & 398,8 & 66,5 \\
\hline 36 & Colocar etiqueta a la botella & 34,0 & 37,5 & 39.6 & 41,2 & 38,6 & 33,5 & 224,4 & 37,4 \\
\hline 37 & Limpiar la botella & 27,9 & 30,6 & 31,4 & 32,6 & 32,9 & 28,5 & 183,9 & 30,7 \\
\hline 38 & Armar la caja de empaque & 45,5 & 50,0 & 47,9 & 49,8 & 50,8 & 44,0 & 288,0 & 48,0 \\
\hline 39 & Guardar botela de empaque & 185,1 & 203,6 & 200,2 & 208.2 & 199,0 & 172,4 & 1168,6 & 194.8 \\
\hline 40 & Revisar lote de empacado & 728,5 & 801,3 & 785,8 & 817,2 & 778,7 & 674,9 & 4586,4 & 764,4 \\
\hline 41 & Almacenar en la bodega & 305.6 & 336.2 & 340,5 & 354.1 & 336,0 & 291,2 & 1963.5 & 3272 \\
\hline
\end{tabular}

Fuente: Los autores.

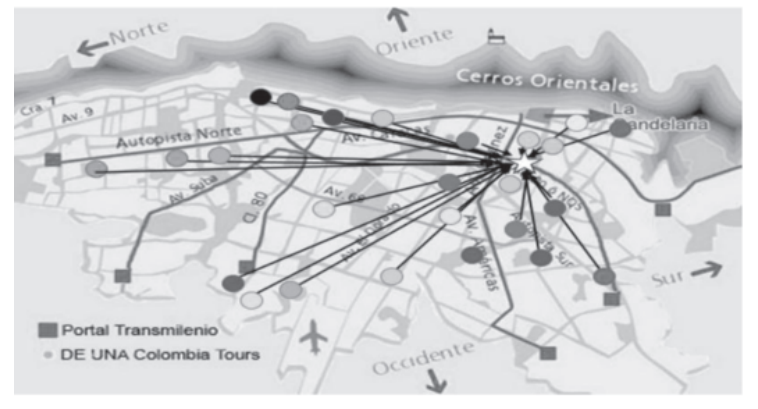

Fig. 5. Mapa de los proveedores de Bodegas Añejas Ltda. Fuente: Los autores. las devoluciones; los centros de distribución se simbolizan con 2 estrellas grises y la planta de manufactura esta simbolizada con la estrella blanca.

De acuerdo con los procesos definidos en el modelo SCOR. realizados en Bodegas Añejas Ltda., en la Fig. 5 se puede evidenciar que los proveedores entregan la materia prima por orden de compra (D2) a la empresa y reciben devoluciones de materia prima defectuosa (DR1). Al llegar a la planta, la materia prima se recibe por orden de compra (S1), 
54 REVISTA INGENIERÍA, MATEMÁTICAS Y CIENCIAS DE LA INFORMACIÓN

Tabla V. Diagrama de flujo Bodegas Añejas Ltda.

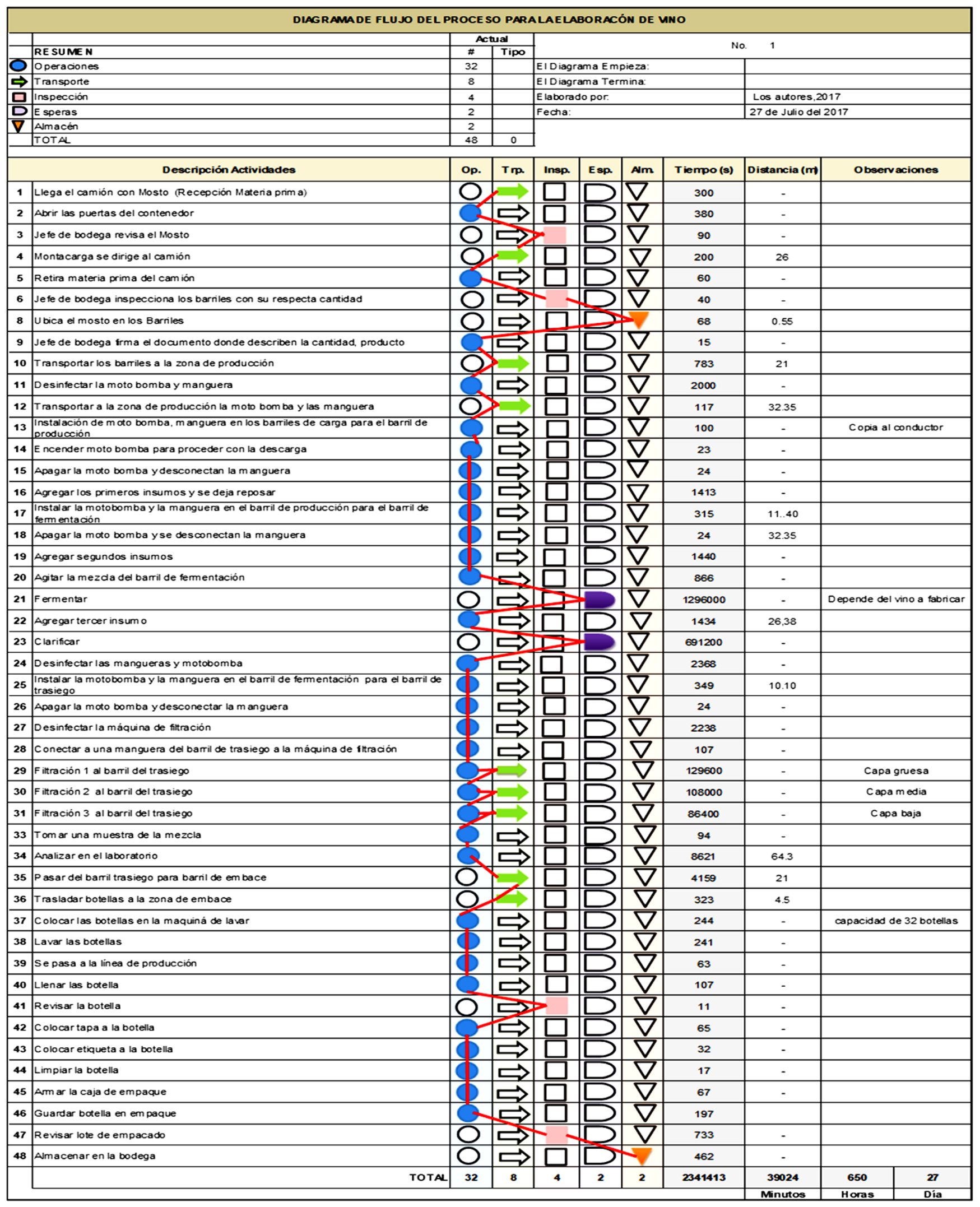

Fuente: Los autores. 


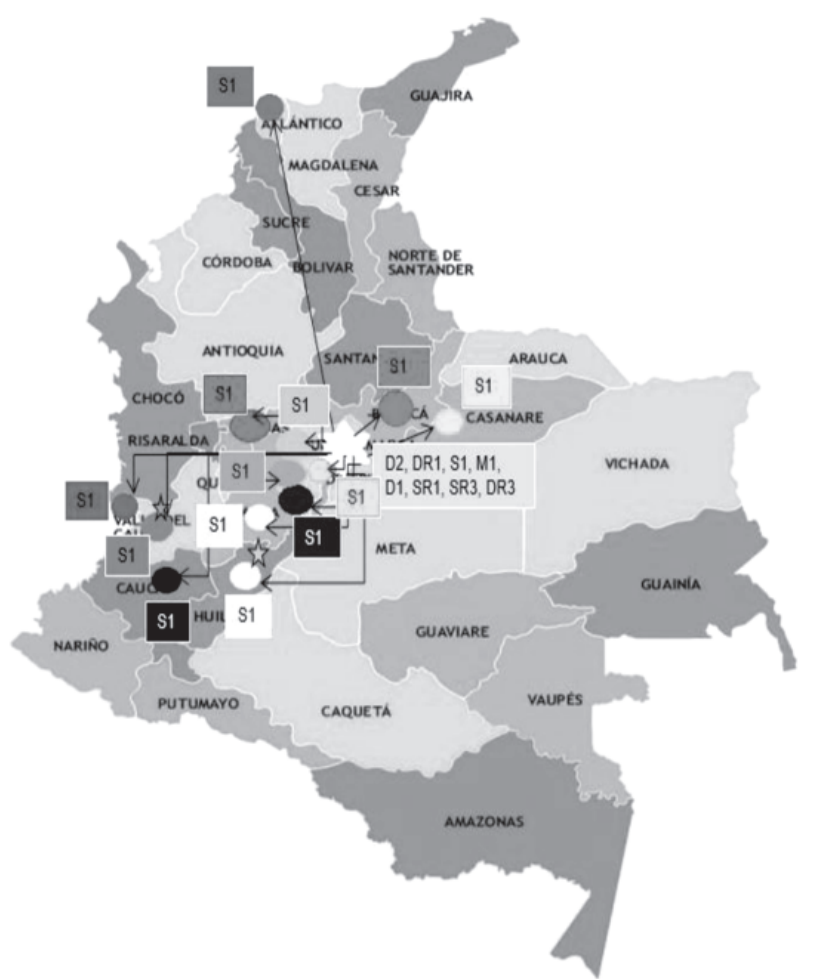

Fig. 6. Mapa de los proveedores de Bodegas Añejas Ltda. Fuente: Los autores.

se fabrica el producto nuevo para inventario (M1) y termina con la distribución a los clientes y a sus centros regionales de distribución (D1). En la Fig. 6, los clientes compran producto para reabastecer su inventario (S1), si el producto es defectuoso se devuelve a la planta de manufactura (SR1), también, si se recibió producto por exceso se devuelve al centro de distribución (SR3); la planta de manufactura o el centro de distribución reciben las devoluciones y dispone que si es por exceso de producto enviado (DR3) se re almacena, pero si es por defecto del producto (SR1) se debe enviar directamente a la planta de manufactura para su respectivo proceso.

El resultado de la aplicación del modelo SCOR. fue la definición de las desconexiones y oportunidades de mejora, en la Tabla VI se identifican dichas desconexiones y se establecen las buenas prácticas que permiten evaluar el rendimiento de la cadena de suministro para el mejoramiento de los procesos.

Para el segundo momento, se realiza la clasificación $\mathrm{ABC}$, herramienta que permite la identificación de todos los productos del inventario en tres categorías según su grado de importancia, rotación y participación en el ingreso. Las categorías son: alta (A), representa los artículos a los cuales se les brinda una mayor atención, dedicación de tiempo y esfuerzo; media (B) y baja (C) (Ver Tabla VII). Para su aplicación, se consolidó la información en una base de datos con las ventas de los productos en los años 2015 y 2016, se ordenan los productos de acuerdo con su volumen de ventas de mayor a menor y se calcula el porcentaje acumulado con respecto a las ventas totales. Este proceso permitió mejorar la distribución física de los productos en la bodega (Ver Tabla VIII).

En el gráfico 1, se observa la distribución de los productos en las diferentes categorías. En el tipo A representa el $76 \%$ del valor neto de ventas del

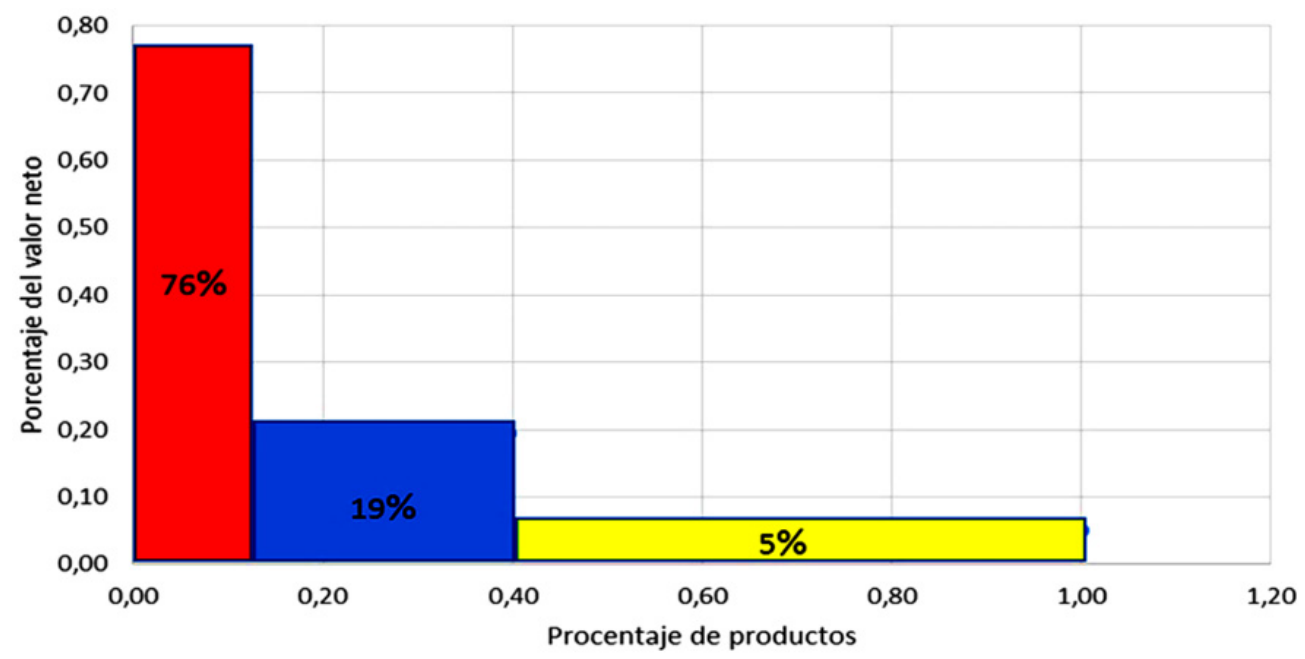

Gráfico 1. Clasificación ABC del 2016. Fuente: Los autores. 
Tabla VI. Desconexión y estrategia para Bodegas Añejas Ltda.

\begin{tabular}{|c|c|}
\hline Desconexión & Estrategia \\
\hline $\begin{array}{l}\text { En el segundo semestre del año Bodega } \\
\text { Añejas Ltda. excede la capacidad de la } \\
\text { planta con respecto a la producción }\end{array}$ & $\begin{array}{l}\text { - Examinar tamaño del stock de capacidad } \\
\text { - Estimar los requisitos futuros de capacidad } \\
\text { - Desarrolla un pronóstico de producción y demanda para tener } \\
\text { planificado cual va a ser la capacidad de la planta } \\
\text { - Desarrollar planes alternativos para cubrir esas brechas } \\
\text { - Determinar políticas de inventario que permitan identificar cuando se } \\
\text { presentan excesos de producto }\end{array}$ \\
\hline $\begin{array}{l}\text { Por la alta producción del segundo } \\
\text { semestre del año se genera un costo de } \\
\text { mano de obra innecesaria }\end{array}$ & $\begin{array}{l}\text { - Implementar el sistema de mejora continua kaizen } \\
\text { - Pronosticar las ventas para tener planificado el volumen a producir } \\
\text { - Reducir espacio utilizado }\end{array}$ \\
\hline $\begin{array}{l}\text { La bodega guarda el inventario de materia } \\
\text { prima, productos terminados y productos } \\
\text { a distribuir juntos, generando mal } \\
\text { almacenamiento }\end{array}$ & $\begin{array}{l}\text { - Realizar un rediseño de la bodega para almacenar los productos de } \\
\text { una mejor manera } \\
\text { - Involucrar a la dirección dando seguimiento a los planes y programa } \\
\text { para la implementación de las buenas prácticas de manufactura (BPM) } \\
\text { - Diseñar adecuadamente la bodega con su respectiva división de áreas } \\
\text { - Disponer de claras y precisas instrucciones de higiene de las áreas y } \\
\text { designar un responsable de las tareas de limpieza } \\
\text { - Almacenar los productos sobre tarimas apilados lejos de las paredes, } \\
\text { de manera de no ser un obstáculo para la limpieza del almacén } \\
\text { - Involucrar al personal para llevar a cabo las áreas y cumplimiento de } \\
\text { las políticas } \\
\text { - Establecer la frecuencia de revisión de esos materiales y productos } \\
\text { para verificar su estado de limpieza, cómo operar para que estén aptos } \\
\text { - Eara su uso } \\
\text { idecutar un sistema de trazabilidad y retiro de producto que permita la } \\
\text { - Ejecutar un plan de Buenas Prácticas de Almacenamiento }\end{array}$ \\
\hline $\begin{array}{l}\text { Bodegas Añejas Ltda. posee y opera dos } \\
\text { centros de distribución en Ibagué y Cali, } \\
\text { donde generan un sobrecosto por lo que } \\
\text { no llega el producto directamente al } \\
\text { cliente }\end{array}$ & $\begin{array}{l}\text { - Analizar los costos que se tienen por los centros de distribución para } \\
\text { compararlos con los costos que se puedan generar sin tener los centros } \\
\text { de distribución } \\
\text { - Planificar una solución alternativa con los centros de distribución } \\
\text { - Hacer seguimiento a estos costos para mantener un equilibrio }\end{array}$ \\
\hline $\begin{array}{l}\text { No se tiene un canal de retorno para la } \\
\text { mercancía }\end{array}$ & $\begin{array}{l}\text { - Generar políticas de devoluciones y garantías } \\
\text { - Todo manejo de devoluciones debe efectuarse acorde a } \\
\text { procedimientos escritos } \\
\text { - Ejecutar una logística inversa en el flujo de los productos desde el } \\
\text { punto de consumo hasta el punto de origen de una forma eficiente } \\
\text { - Establecer proceso para la programación y recepción de las } \\
\text { devoluciones } \\
\text { - Enviar electrónicamente al encargado en el punto de venta la } \\
\text { autorización de la devolución, el horario de retorno y los documentos } \\
\text { de embarque para agilizar el proceso }\end{array}$ \\
\hline $\begin{array}{l}\text { Deficiente gestión y control de } \\
\text { almacenamiento de producto terminado }\end{array}$ & $\begin{array}{l}\text { - Calcular dinámicamente el inventario de seguridad basado en ventas } \\
\text { actuales } \\
\text { - Controlar derrames }\end{array}$ \\
\hline
\end{tabular}

Fuente: Los autores. 
Tabla VII. Clasificación ABC

\begin{tabular}{|c|c|c|l|}
\hline ZONA & \% DE INVENTARIO & $\%$ DE VENTAS & \multicolumn{1}{c|}{ OBSERVACIÓN } \\
\hline A & $15 \%$ & $70 \%-80 \%$ & $\begin{array}{l}\text { Es la zona más importante ya que por su costo elevado } \\
\text { genera un gran aporte a las utilidades de la compañía. }\end{array}$ \\
\hline B & $25 \%-30 \%$ & $15 \%-25 \%$ & $\begin{array}{l}\text { Es la zona con importancia secundaria donde se } \\
\text { controlan sus existencias y pueden ascender a la zona a } \\
\text { o descender a la zona c. }\end{array}$ \\
\hline C & $60 \%-65 \%$ & $\begin{array}{l}\text { Es la zona poco importante ya que representa la } \\
\text { mayoría del volumen del inventario, pero con poca } \\
\text { utilidad para la empresa. }\end{array}$ \\
\hline
\end{tabular}

Fuente: Los autores.

Tabla VIII. Clasificación ABC 2016.

\begin{tabular}{|c|c|c|c|c|c|c|c|}
\hline \multicolumn{8}{|c|}{ CLASIFICACION ABC DEL AÑO 2016} \\
\hline Producto & $\begin{array}{l}\text { Centimetros } \\
\text { Cúbicos }\end{array}$ & Unidades & Valor por año & \begin{tabular}{|c|}
$\begin{array}{c}\text { Porcentaje } \\
\text { del valor } \\
\text { total }\end{array}$ \\
\end{tabular} & $\begin{array}{l}\text { Porcentaje } \\
\text { acumulado }\end{array}$ & $\begin{array}{c}\text { Valor por año en } \\
\text { pesos }\end{array}$ & Clasificación \\
\hline UNO BLANCODE COCINA & $750 \mathrm{CC}$ & 24791 & $\$ 1.988 .484 .635,00$ & $48,48 \%$ & $48,48 \%$ & & \\
\hline UNO MOSCATO PASST O & $1000 \mathrm{CC}$ & 55315 & $\$ 471.380 .035,00$ & $11,49 \%$ & $59,97 \%$ & $\$ 3.099 .138 .933,00$ & A \\
\hline UNO MOSCATO PASST O & $750 \mathrm{CC}$ & 45597 & $\$ 376.530 .262,00$ & $9,18 \%$ & $69,15 \%$ & & \\
\hline UNOESPUMOSO CASANOVAROSADO & $750 \mathrm{CC}$ & 29825 & $\$ 263.344 .001,00$ & $6,42 \%$ & $75,57 \%$ & $16 \%$ & $11 \%$ \\
\hline UNO MOSCATOPASST O & $2000 \mathrm{CC}$ & 11383 & $\$ 207.644 .672,00$ & $5,06 \%$ & $80,63 \%$ & \multirow{5}{*}{$\$ 796.438 .105,00$} & \multirow{5}{*}{ B } \\
\hline UNO ESPUMOSO CASANOVABLANCO & $750 \mathrm{CC}$ & 17497 & $\$ 157.943 .474,00$ & $3,85 \%$ & $84,48 \%$ & & \\
\hline UNOMISA & $750 \mathrm{CC}$ & 10636 & $\$ 93.363 .953,00$ & $2,28 \%$ & $86,76 \%$ & & \\
\hline UNOREGINAPORT 7 & $750 \mathrm{CC}$ & 11158 & $\$ 76.322 .976,00$ & $1,86 \%$ & $88,62 \%$ & & \\
\hline UNOBLANCO DE COCINA & $2000 \mathrm{CC}$ & 3127 & $\$ 59.685 .595,00$ & $1,46 \%$ & $90,08 \%$ & & \\
\hline UNODE COCINAT INTO & $750 \mathrm{CC}$ & 6812 & $\$ 55.136 .253,00$ & $1,34 \%$ & $91,42 \%$ & \multirow{5}{*}{$19 \%$} & \multirow{5}{*}{$29 \%$} \\
\hline UNO DE CEREZADE GALA & $750 \mathrm{CC}$ & 5350 & $\$ 46.756 .024,00$ & $1,14 \%$ & $92,56 \%$ & & \\
\hline UNO ESPUMOSO CASANOVAROSADO & $2500 \mathrm{CC}$ & 1229 & $\$ 37.364 .697,00$ & $0,91 \%$ & $93,47 \%$ & & \\
\hline UNOVERMOUTH BLANCO & $750 \mathrm{CC}$ & 3694 & $\$ 31.627 .147,00$ & $0,77 \%$ & $94,24 \%$ & & \\
\hline UNO BLANCO DE COCINA & $375 \mathrm{CC}$ & 6554 & $\$ 30.593 .314,00$ & $0,75 \%$ & $94,99 \%$ & & \\
\hline UNO MOSCATO PASST O & $350 \mathrm{CC}$ & 6197 & $\$ 30.249 .601,00$ & $0,74 \%$ & $95,73 \%$ & \multirow{13}{*}{$\$ 205.517 .416,00$} & \multirow{13}{*}{ C } \\
\hline UNO MOSCATO PASST O & $1500 \mathrm{CC}$ & 1992 & $\$ 29.965 .554,00$ & $0,73 \%$ & $96,46 \%$ & & \\
\hline UNODE COCINAT INTO & $2000 \mathrm{CC}$ & 1502 & $\$ 28.857 .370,00$ & $0,70 \%$ & $97,16 \%$ & & \\
\hline UNOVERMOUTH BLANCO & $2000 \mathrm{CC}$ & 1527 & $\$ 27.729 .425,00$ & $0,68 \%$ & $97,84 \%$ & & \\
\hline UNOVERMOUTH ROJO PICASSI & $750 \mathrm{CC}$ & 1679 & $\$ 15.495 .321,00$ & $0,38 \%$ & $98,21 \%$ & & \\
\hline UNOREGINAPORT 7 & $2000 \mathrm{CC}$ & 704 & $\$ 11.775 .780,00$ & $0,29 \%$ & $98,50 \%$ & & \\
\hline UNO DE COCINATINTO & $350 \mathrm{CC}$ & 2446 & $\$ 11.328 .331,00$ & $0,28 \%$ & $98,78 \%$ & & \\
\hline UNO REGINAPORT 7 & $1500 \mathrm{CC}$ & 787 & $\$ 10.834 .699,00$ & $0,26 \%$ & $99,04 \%$ & & \\
\hline UNOVERMOUTH ROJO PICASSI & $1000 \mathrm{CC}$ & 907 & $\$ 8.091201,00$ & $0,20 \%$ & $99,24 \%$ & & \\
\hline UNO ESPUMOSO CASANOVABLANCO & $2500 \mathrm{CC}$ & 232 & $\$ 7.100 .752,00$ & $0,17 \%$ & $99,41 \%$ & & \\
\hline UNO ESPUMOSO CASA VEJAROSADO & $2500 \mathrm{CC}$ & 169 & $\$ 4.922 .570,00$ & $0,12 \%$ & $99,53 \%$ & & \\
\hline UNO DE CEREZADE GALA & $1500 \mathrm{CC}$ & 324 & $\$ 4.905 .519,00$ & $0,12 \%$ & $99,65 \%$ & & \\
\hline UNO ESPUMOSO CASANOVAROSADO & $2000 \mathrm{CC}$ & 143 & $\$ 4.176 .195,00$ & $0,10 \%$ & $99,75 \%$ & & \\
\hline UNO ESPIMOSO CASANOVABLANCO & $2000 \mathrm{CC}$ & 101 & $\$ 2.808 .175,00$ & $0,07 \%$ & $99,82 \%$ & \multirow{8}{*}{$5 \%$} & \multirow{8}{*}{$60 \%$} \\
\hline UNO ESPUMOSO CASA MEJABLANCO & $2500 \mathrm{CC}$ & 84 & $\$ 2.536 .635,00$ & $0,06 \%$ & $99,88 \%$ & & \\
\hline UNO BLANCODE COCINA & $1500 \mathrm{CC}$ & 155 & $\$ 2.352 .522,00$ & $0,06 \%$ & $99,94 \%$ & & \\
\hline UNO ESPUMOSO CASA VEJAROSADO & $2000 \mathrm{CC}$ & 48 & $\$ 1.290266,00$ & $0,03 \%$ & $99,97 \%$ & & \\
\hline UNO BLANCO SECO DE MESA & $750 \mathrm{CC}$ & 99 & $\$ 851.500,00$ & $0,02 \%$ & $99,99 \%$ & & \\
\hline UNO BLANCO DE MESA & $2000 \mathrm{CC}$ & 11 & $\$ 193.000,00$ & $0,00 \%$ & $0,00 \%$ & & \\
\hline UNO DE MANZANILLAFLAMENCADULCE & $750 \mathrm{CC}$ & 5 & $\$ 37.000,00$ & $0,00 \%$ & $0,00 \%$ & & \\
\hline UNO SOBERANO & $750 \mathrm{CC}$ & 2 & $\$ 16.000,00$ & $0,00 \%$ & $0,00 \%$ & & \\
\hline UNO DE MANZANILLAFLAMENCASECO & $750 \mathrm{CC}$ & 0 & $\$ 0,00$ & $0,00 \%$ & $0,00 \%$ & \multirow{5}{*}{$\$ 0,00$} & \multirow{5}{*}{$\begin{array}{l}\text { Productos } \\
\text { retirados }\end{array}$} \\
\hline UNO GRAN PODER & $2000 \mathrm{CC}$ & 0 & $\$ 0,00$ & $0,00 \%$ & $0,00 \%$ & & \\
\hline UNO GRAN PODER & $750 \mathrm{CC}$ & 0 & $\$ 0,00$ & $0,00 \%$ & $0,00 \%$ & & \\
\hline UNO SOBERANO & $2000 \mathrm{CC}$ & 0 & $\$ 0,00$ & $0,00 \%$ & $0,00 \%$ & & \\
\hline UNO VERMOUTH ROJO PICASSI & $2000 \mathrm{CC}$ & 0 & $\$ 0,00$ & $0,00 \%$ & $0,00 \%$ & & \\
\hline Total & & 252082 & $\$ 4.101 .694 .454,00$ & $100,00 \%$ & & $\$ 4.101 .694 .455,00$ & \\
\hline
\end{tabular}

Fuente: Los autores. 
año 2016, en él se encuentran: El vino Moscato Passito en sus presentaciones 1000 CC y 750 CC, el Casanova rosado espumoso en $750 \mathrm{CC}$ y el vino Blanco de cocina en 750 CC. La política de la empresa es retirar del mercado los productos que no generen un margen de utilidad establecido, que se encuentran en la categoría $C$, estos son vino de manzanilla flamenca seco en $750 \mathrm{CC}$, vino gran poder en 2000 CC y 750 CC, vino soberano 2000 CC y vino Vermouth rojo picassi en 2000CC.

Avanzando en el tercer momento para el desarrollo del sistema de gestión de almacenamiento se verifican las dimensiones de Bodegas Añejas Ltda., y se establece la superficie de la zona de producción y almacenamiento en $812,2475 \mathrm{~m}^{2}$ dividida en 6 áreas: Recibo de materia prima, proceso de filtrado, de envasado, almacenamiento de materia prima y producto terminado, la cafetería y baño. El punto de venta se encuentra en frente de la zona de producción y almacenamiento y las oficinas administrativas en el segundo y tercer piso de la empresa. En la Fig. 7 y la Tabla IX se presentan las dimensiones y el área ocupada por cada zona.

Se realiza la evaluación de los mecanismos que se utilizan para el almacenamiento de los productos teniendo como referencia las áreas delimitadas. En la Tabla X, se describe los aspectos evaluados en una escala de bajo, regular y bueno, incluyendo las observaciones que complementan la valoración asignada.

Con los resultados obtenidos, se inicia el cuarto momento, que consiste en desarrollar el método SLP. de Muther para mejorar la distribución de la planta, reorganizando los espacios con las

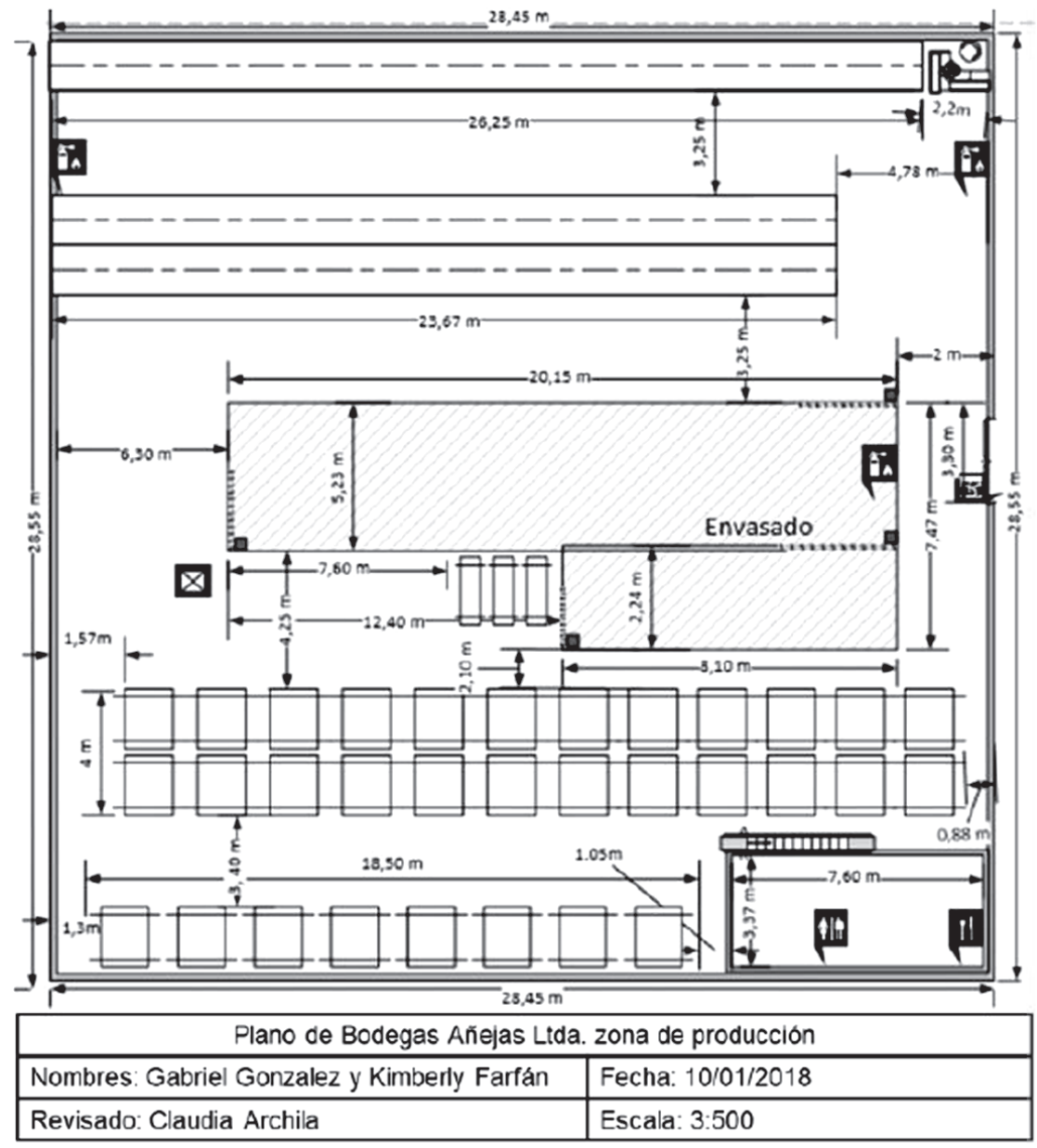

Fig. 7. Plano de la zona de producción y almacenamiento de Bodegas Añejas Ltda. 2017. Fuente: Los autores. 
Tabla IX. Dimensiones zona de producción Bodegas Añejas Ltda.

\begin{tabular}{|c|c|c|c|}
\hline Áreas & Área 1 $\left(\mathrm{m}^{2}\right)$ & Área 2 $\left(\mathrm{m}^{2}\right)$ & Área Total $\left(\mathrm{m}^{2}\right)$ \\
\hline Recepción de materia prima & - & - & 25,08 \\
\hline Zona de envasado & 105,38 & 18,14 & 123,52 \\
\hline Zona de filtrado & 104 & 125,245 & 229,245 \\
\hline $\begin{array}{c}\text { Almacenamiento producto terminado y materia } \\
\text { prima }\end{array}$ & 124,69 & 71,01 & 195,7 \\
\hline Cafetería y Baño & - & - & 25,612 \\
\hline Área Total & - & - & 812,247 \\
\hline
\end{tabular}

Fuente: Los autores.

Tabla X. Evaluación de mecanismos de almacenamiento de Bodegas Añejas Ltda.

\begin{tabular}{|c|c|c|c|c|}
\hline Elemento & Bajo & Regular & Bueno & Observación \\
\hline $\begin{array}{l}\text { Zona de la recepción y entrega de } \\
\text { producto }\end{array}$ & & $x$ & & No se observa ninguna señalización \\
\hline Montacarga & & $\mathrm{X}$ & & $\begin{array}{llll}\text { Se encuentra } & \text { sucio, } & \text { sin } \\
\text { mantenimiento } & & \\
\end{array}$ \\
\hline Transpaleta & & & $X$ & $\mathrm{~N} / \mathrm{A}$ \\
\hline Carretilla & & $X$ & & $\begin{array}{l}\text { Su plataforma de madera se nota } \\
\text { desgastada falta de mantenimiento }\end{array}$ \\
\hline Pasillos & $x$ & & & $\begin{array}{l}\text { Falta de codificación en los pasillos; } \\
\text { obstaculización de rejas, escaleras, } \\
\text { cajas; la entrada y salida es la misma }\end{array}$ \\
\hline $\begin{array}{l}\text { Zona de almacenamiento de materia } \\
\text { prima }\end{array}$ & & & $\mathrm{X}$ & $\begin{array}{l}\text { Se encuentra una ubicación exacta } \\
\text { para esos productos }\end{array}$ \\
\hline $\begin{array}{l}\text { Materia prima: Uvas pasas, insumos de } \\
\text { aseo y cafetería, harina, yema de huevo, } \\
\text { gelatina tipo C, levadura, azúcar, leche y } \\
\text { sal }\end{array}$ & & & $\mathrm{X}$ & N/A \\
\hline Zona de almacenamiento - cajas & $x$ & & & $\begin{array}{l}\text { No se encuentra un lugar exacto } \\
\text { donde se pueda descargar estas cajas, } \\
\text { ni un orden por tamaño o utilización } \\
\text { de estas, ni señalización }\end{array}$ \\
\hline Cajas 12 unidades & & & $x$ & N/A \\
\hline Zona de almacenamiento - botellas & $x$ & & & $\begin{array}{l}\text { No hay un lugar notorio para } \\
\text { depositar las botellas, ni clasificarlas } \\
\text { por material (vidrio o plástico), no } \\
\text { hay señalización }\end{array}$ \\
\hline Botellas vidrio y plástico & & & $x$ & $\mathrm{~N} / \mathrm{A}$ \\
\hline Zona de almacenamiento - químico & $x$ & & & $\begin{array}{l}\text { No se observa etiquetas de } \\
\text { peligrosidad, no tiene señalización, } \\
\text { deficiencia en orden dentro del } \\
\text { almacén, no existe cerca un extintor, } \\
\text { dentro de este también se almacena } \\
\text { la materia prima de tapas }\end{array}$ \\
\hline $\begin{array}{l}\text { Químicos: Ácido cítrico, acido tartárico, } \\
\text { bentonita, fosfato de amonio, meta, } \\
\text { bisulfito de } \mathrm{K} \text {, sorbato de potasio, goma } \\
\text { xantana, benzato en } \mathrm{Na} \text {, sal nitro, ácido } \\
\text { Ascórbico }\end{array}$ & & & $\mathrm{X}$ & $\begin{array}{l}\text { Se adquiere fichas técnicas de cada } \\
\text { químico }\end{array}$ \\
\hline
\end{tabular}


Continuación Tabla X.

\begin{tabular}{|c|c|c|c|c|}
\hline Elemento & Bajo & Regular & Bueno & Observación \\
\hline Zona de almacenamiento - etiquetado & & $x$ & & $\begin{array}{l}\text { Deficiente orden dentro del almacén } \\
\text { ya que se encuentra dentro del } \\
\text { almacén de químicos sin ninguna } \\
\text { señalización }\end{array}$ \\
\hline Ventilación & & & $x$ & N/A \\
\hline Zona de filtrado & & $\mathrm{x}$ & & $\begin{array}{l}\text { Poca señalización y mapa visible del } \\
\text { proceso }\end{array}$ \\
\hline Máquina estrujadora - despalilladora & & $x$ & & $\begin{array}{l}\text { Falta de mantenimiento, ubicación } \\
\text { adecuada y no existe una } \\
\text { señalización de área al utilizar la } \\
\text { maquina }\end{array}$ \\
\hline Barricas 33 & & $x$ & & Su base es inestable \\
\hline Motobomba & & $x$ & & $\begin{array}{l}\text { Falta de ubicación para dejar la } \\
\text { motobomba }\end{array}$ \\
\hline Zona de envasado & & & $x$ & N/A \\
\hline Máquina enjugar botella & & & $x$ & $\mathrm{~N} / \mathrm{A}$ \\
\hline Máquina llenada & & & $x$ & $\mathrm{~N} / \mathrm{A}$ \\
\hline Máquina corcho & & & $x$ & $\mathrm{~N} / \mathrm{A}$ \\
\hline Zona de calidad & & $x$ & & $\begin{array}{l}\text { Deficiente señalización para } \\
\text { identificar esta zona }\end{array}$ \\
\hline Etiquetado & & & $x$ & N/A \\
\hline Código de barra & & & $x$ & N/A \\
\hline Cafetería & & $X$ & & \multirow{2}{*}{$\begin{array}{l}\text { Tienen una gran cercanía generando } \\
\text { malestar e incomodidad a los } \\
\text { empleados }\end{array}$} \\
\hline Baño & & $x$ & & \\
\hline $\begin{array}{l}\text { Zona de almacenamiento de producto } \\
\text { terminado }\end{array}$ & & $x$ & & $\begin{array}{l}\text { Deficiente señalización de } \\
\text { clasificación de producto terminado }\end{array}$ \\
\hline Estibas & & & $x$ & N/A \\
\hline Estantería & & $x$ & & $\begin{array}{l}\text { Cada estantería no tiene asociada una } \\
\text { codificación alfabética }\end{array}$ \\
\hline
\end{tabular}

Fuente: Los autores información suministrada por jefe de bodega.

restricciones presentes, la relación entre las áreas, la minimización de los flujos de material, personal e información, lo que permite incrementar la productividad de la empresa.

A continuación, se elabora el plano de la planta a distribuir con la descripción y dimensiones; para tener una visualización completa se presenta la vista isométrica de la zona de producción y almacenamiento realizada en el programa sketchup. (VerFig. VIII). Se desarrolla el plan de distribución detallado (Ver Fig. IX), donde se muestra la secuencia y la cantidad de movimientos durante el proceso como se muestra a continuación:
- Al llegar la materia prima (Uvas pasas hidratada) a la entrada, esta se transporta hacia la máquina de estrujadora/despalilladora tracción manual, para realizar el proceso de estrujado.

- Una vez esté el zumo de la uva pasa se transporta a los barriles de la zona de producción.

- Se transporta la motobomba y las mangueras para realizar el traspaso del zumo de uva a los barriles para empezar el proceso de fermentación. 
- Cuando se está realizando la fermentación, se transportar unos insumos que se debe añadir a la mezcla.

- De los barriles de fermentación se traspasa la mezcla por medio de mangueras y la motobomba a los barriles de trasiego.

- Luego de 12 - 20 días se traspasa la mezcla a los barriles de clarificación.

- De la mezcla se sustrae una muestra, la cual se traslada al laboratorio para analizar la sustancia.

- Esta mezcla aprobada se traspasa a los barriles de filtración.

- Finalizado el proceso, se procede a trasladar a proceso de embotellamiento.

- Terminado el embotellamiento, se traslada las cajas de producto terminado a zona de almacenamiento.

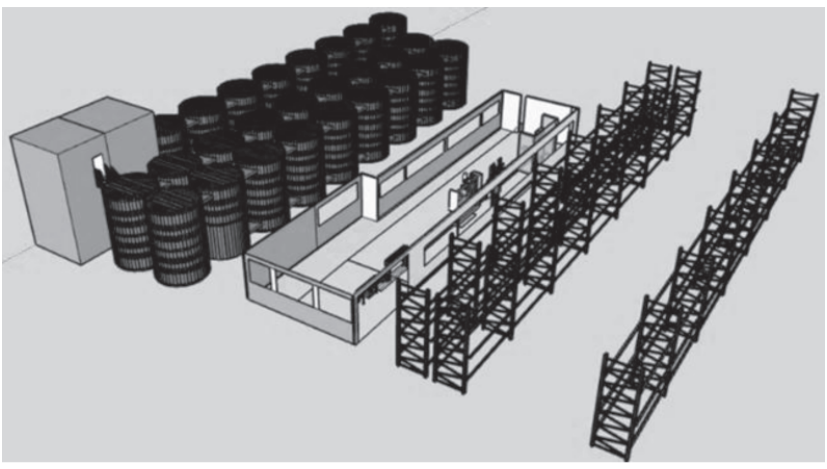

Fig. 8. Vista de la bodega. Fuente: Los autores.

Se desarrolla el diagrama de relación de actividades para el proceso de elaboración de vino que permite representarlas de manera lógica, midiendo la importancia de proximidad entre procesos y áreas, esto se hace mediante un código de letras desarrollado por Muther, aplicándolos en una tabla, en el que se tienen las actividades del proceso de la planta (Ver Fig. 10), se analiza la importancia que hay entre ellas, procediendo a diseñar una figura, que visualiza las relaciones por líneas; dependiendo de la relación de las actividades. (Ver Fig. 11)

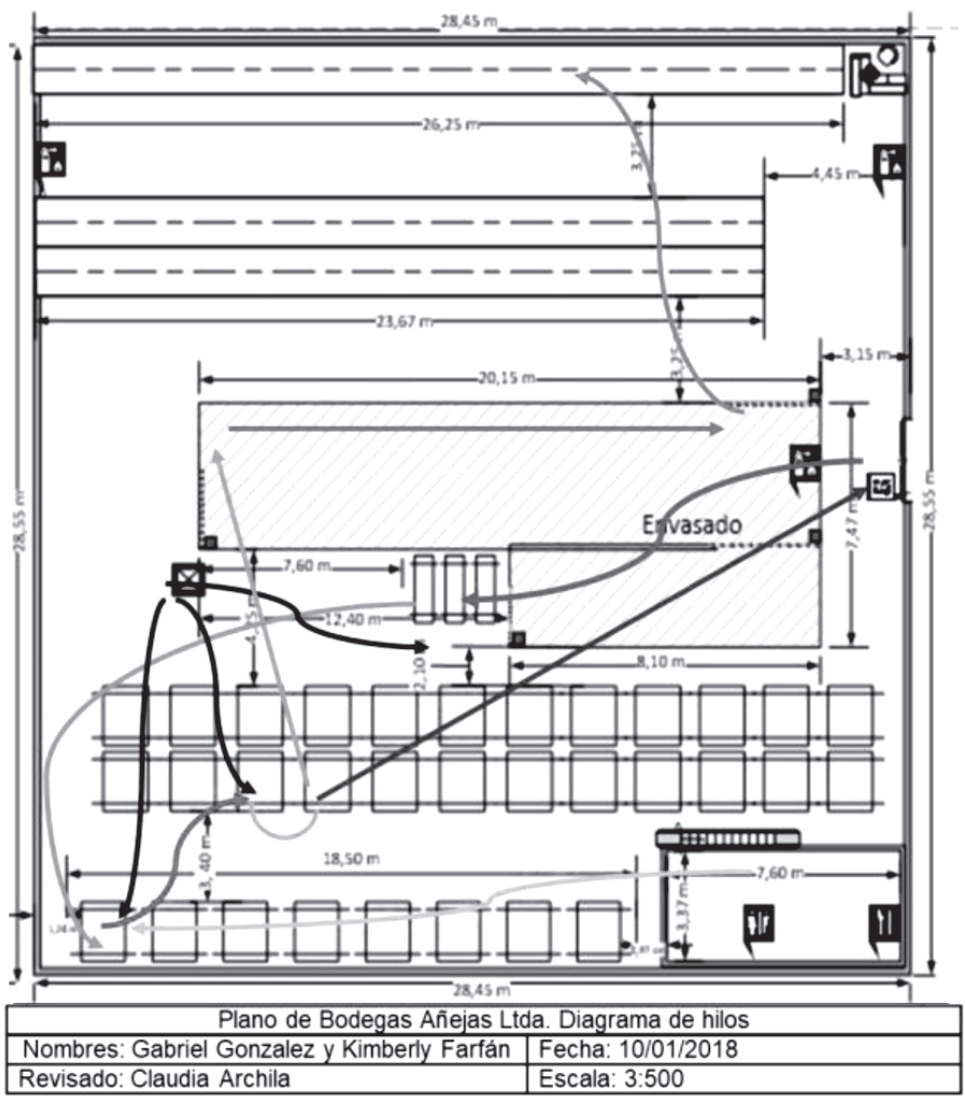

Fig. 9. Diagrama de hilos. Fuente: Los autores. 


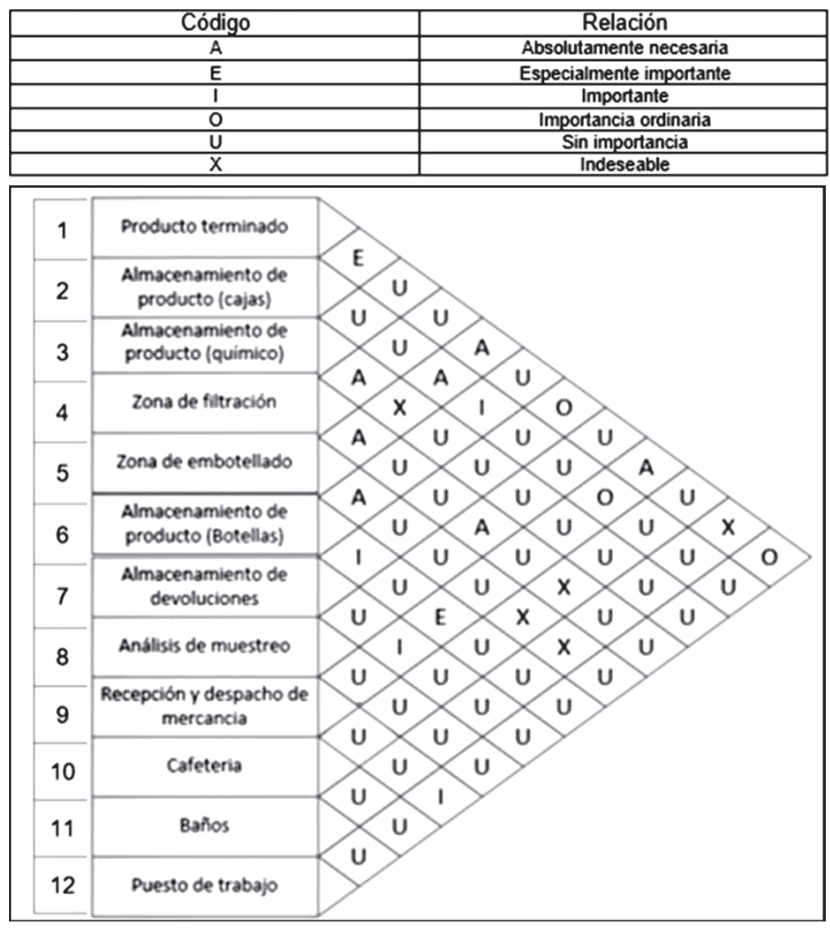

Fig. 10. Diagrama de relaciones de actividades. Fuente: Los autores.

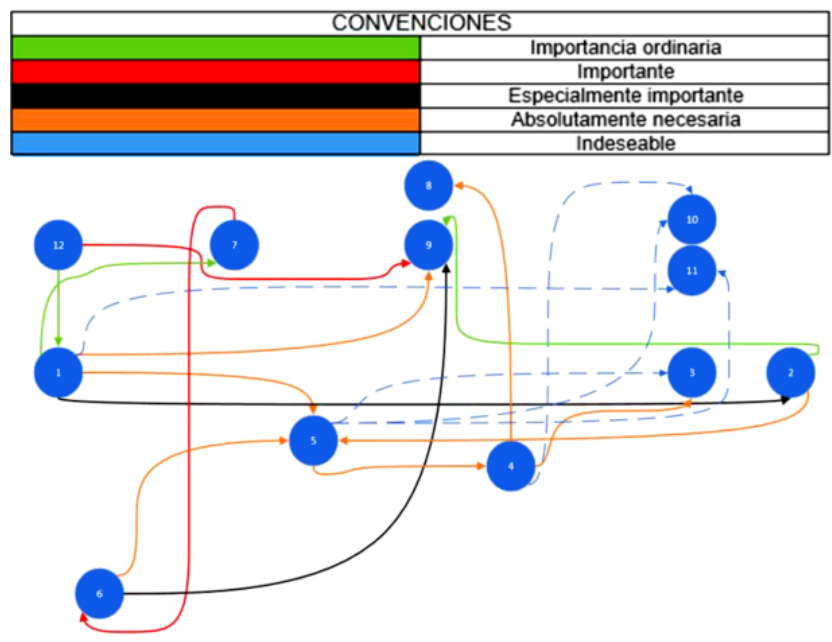

Fig. 11. Diagrama de importancia entre actividades actual. Fuente: Los autores.

\section{Discusión de Resultados}

En esta sección se presentan los resultados obtenidos durante el desarrollo de este proyecto, presentado la propuesta del Sistema de gestión de almacenamiento, cómo se puede observar en la anterior figura, se generan 42 cruces entre las actividades de la zona de producción y almacenamiento actual, generando una inadecuada distribución, para obtener un proceso óptimo se realizan dos alternativas de mejora, a mediano y largo plazo, donde se establecen alternativas factibles de la distribución.

- Diseño propuesto mediano plazo: Teniendo en cuenta algunas limitaciones de la empresa, como lo es, el traspaso de las 35 barricas, y la zona de embotellamiento, por lo que es necesario ayuda de terceros (Maquinaria pesada y remodelación de edificio) no es viable un cambio radical; en la figura 12 se presenta la propuesta para el mediano plazo.

La información obtenida en el diagnóstico permite clasificar las necesidades de la bodega para presentar la propuesta 1 de rediseño que se observa en la fig. 13, donde se tiene opciones que permitan adecuar la disposición de los elementos del ciclo productivo, con el fin de mejorar la productividad; disminuyendo los cruces de 43 a 25, moviendo la actividad 2 (Almacenamiento de cajas) y 6 (Almacenamiento de botellas) de lugar, estas serán colocándolas juntas en una estantería nueva construida en la parte del frente de la zona de embotellado para que a la hora de acceder a estas, mejore el proceso de transporte a la elaboración de vino, por último, construir una salida en la parte de atrás de la estantería con el fin de que los vehículos de transporte tengan facilidad de acceso a la zona de almacenamiento y a la zona de embotellado.

El diagrama de importancia para la propuesta 1 se puede visualizar en la Fig. 14 donde se muestra el rediseño con las modificaciones realizadas y en la Fig. 15 se menciona los beneficios desarrollados a mediano plazo.

- Diseño propuesto largo plazo: Se presenta un nuevo rediseño que aproveche los aportes de la propuesta 1 (Ver fig. 16), se disminuye 22 cruces de la propuesta a mediano plazo, moviendo la actividad 2 (Almacenamiento de cajas) y 6 (Almacenamiento de botellas) colocadas en la nueva estantería frente a la zona de embotellado; actividad 7 (Almacenamiento de devoluciones) en la última estantería de la zona de almacenamiento de producto terminado con la facilidad

Rev. Ingeniería, Matemáticas y Ciencias de la Información Vol. 6 / Núm. 11 / enero - junio de 2019; pág. 45-71 

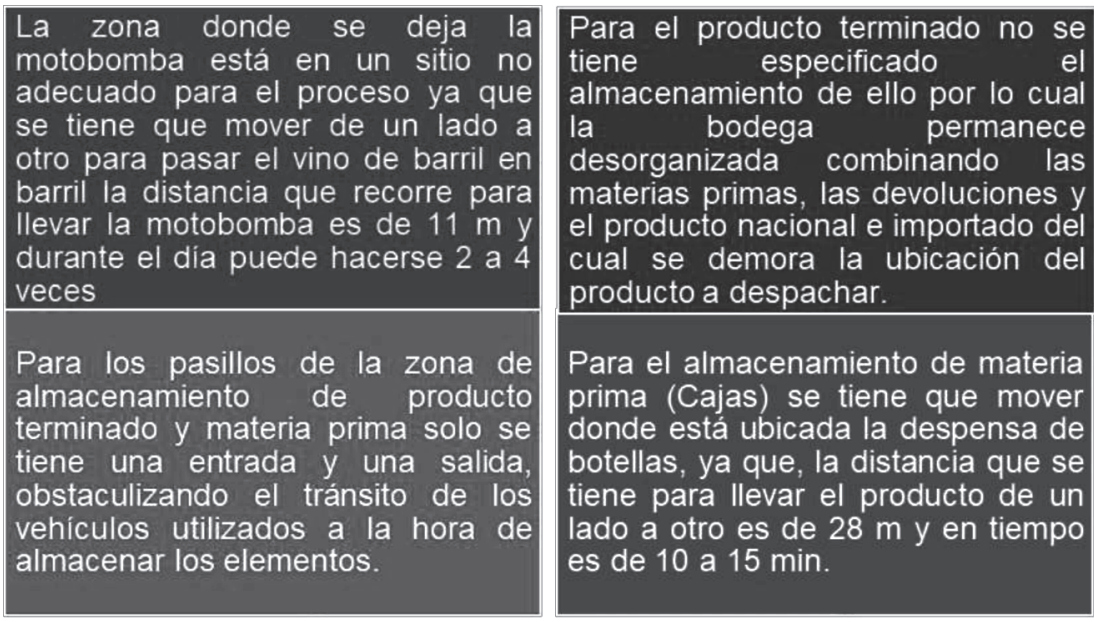

Donde se ubica el almacenamiento

de materia prima de botellas es un

espacio obsoleto donde se

evidencia el desorden y el bloqueo

del montacarguista cuando tiene

que pasar a trasladar producto.

Fig. 12. Cambios propuestos a mediano plazo. Fuente: Los autores.

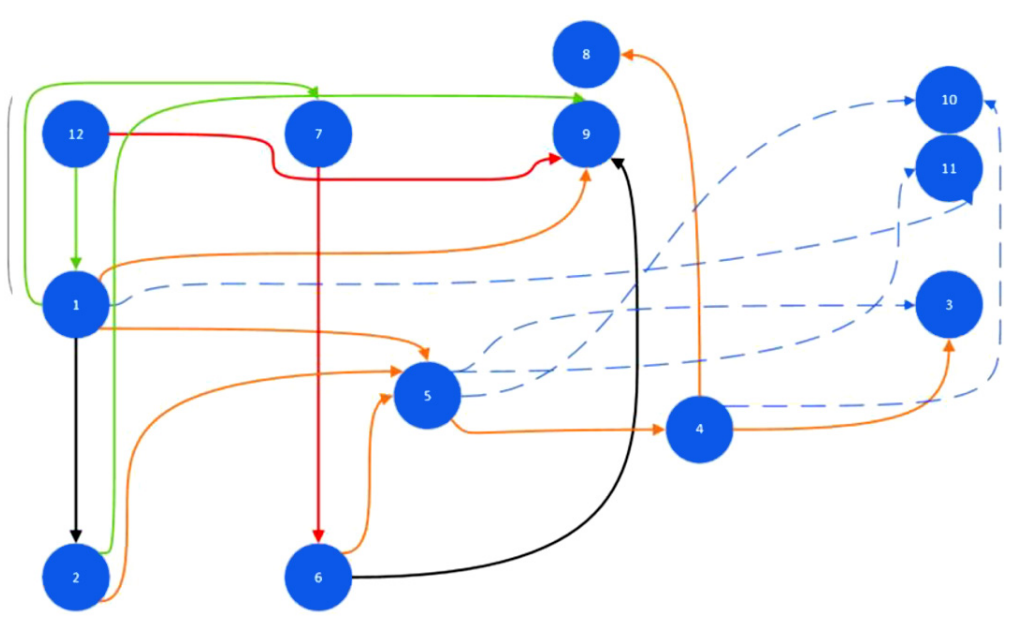

Fig. 13. Propuesta 1 - Diagrama de importancia entre actividades. Fuente: Los autores.

de acceso de vehículo de transporte a la hora de entrar a esta; actividad 8 (Análisis de muestreo) y 3 (Almacenamiento de químicos) se traspasa al segundo piso ya que son esenciales en el proceso de filtración; y la actividad 10 (Cafetería) y 11 (Baños) en la parte trasera de la zona de filtración.

Como resultado, se visualiza el plano del rediseño con la propuesta 2 (Ver fig. 17), reorganizando mejor la estantería incluyendo toda la ma- teria prima (Botellas y cajas), producto terminado y devoluciones, se reformó la parte de los baños y la cafetería para organizar la materia prima (Químicos) y mover la zona de análisis de muestreo a la zona de producción (Ver fig.18).

Los beneficios obtenidos con este rediseño a largo plazo se pueden observar en la Fig. 19.

Y para el último momento se realiza la validación a través del software Flexsim; la simulación 


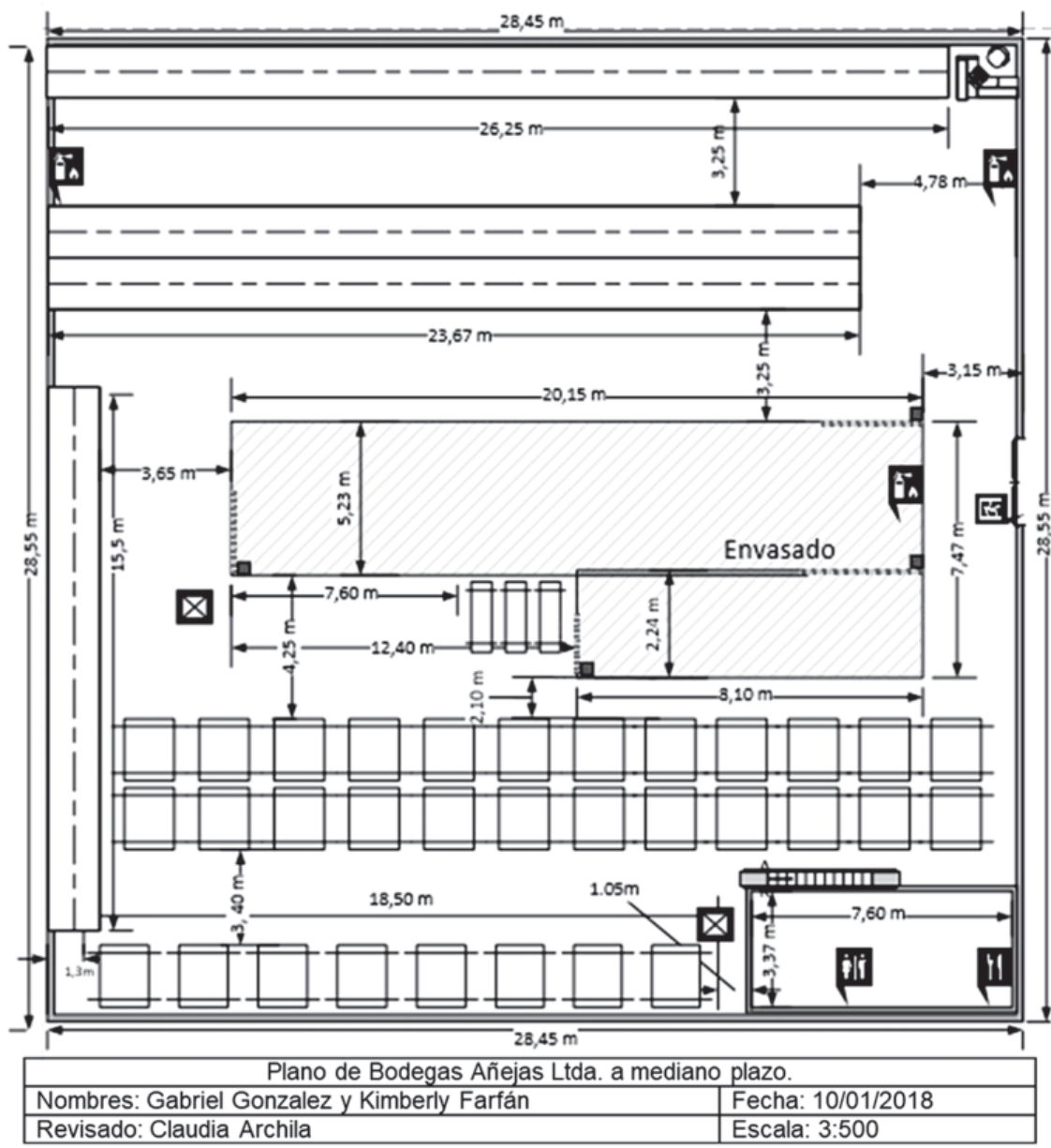

Fig. 14. Propuesta 1 - Plano actualizado. Fuente: Los autores.

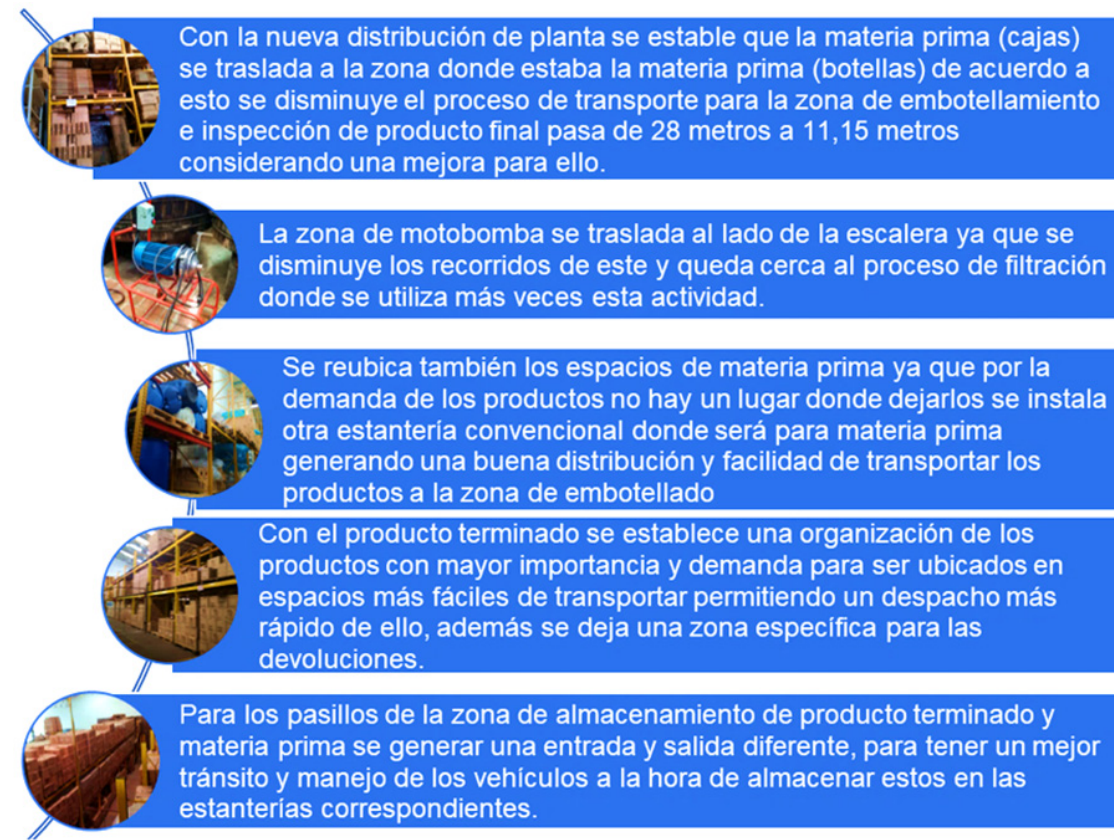

Fig. 15. Beneficios a mediano plazo para Bodegas Añejas Ltda. Fuente: Los autores. 


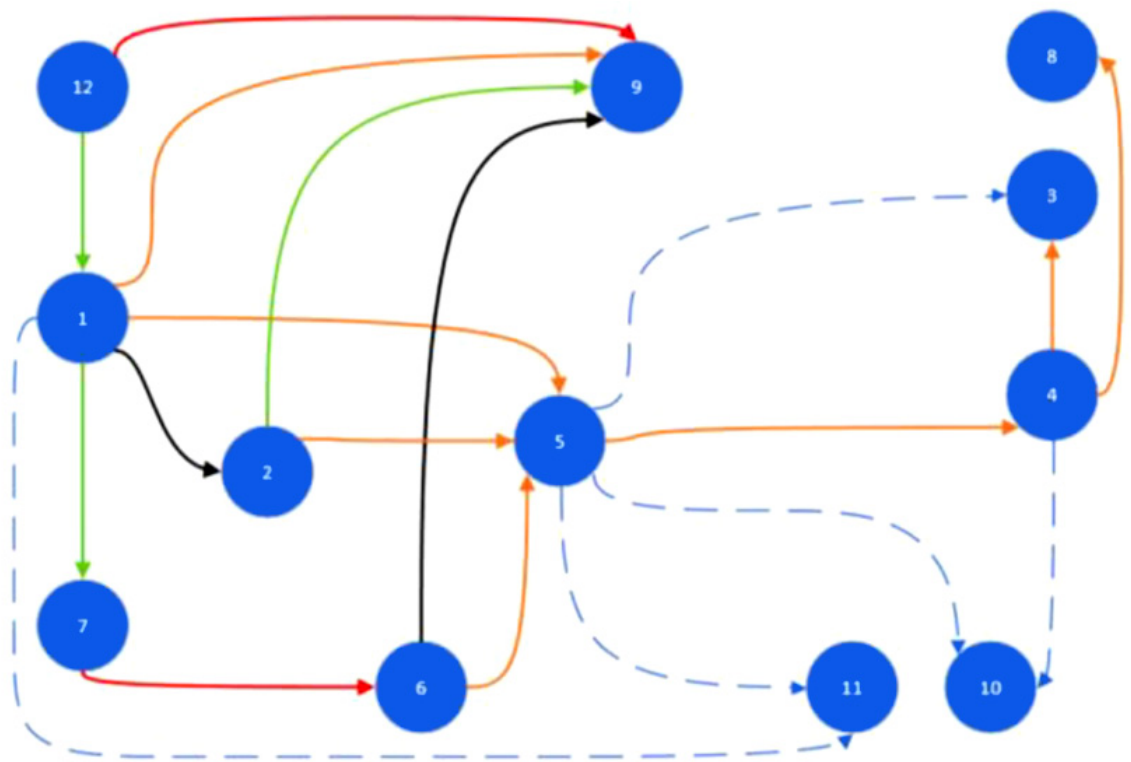

Fig. 16. Propuesta 2 - Diagrama de importancia entre actividades. Fuente: Los autores.

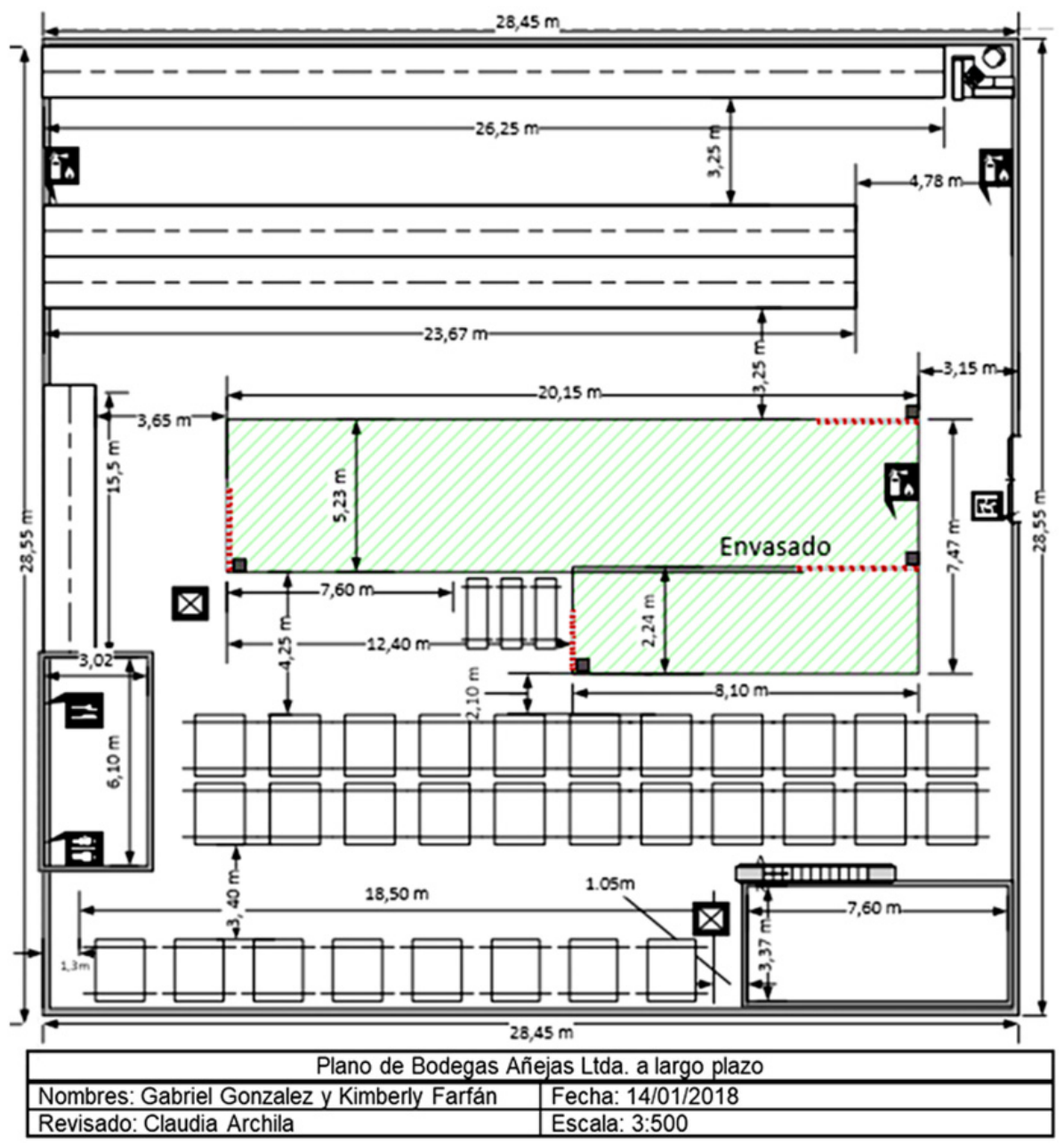

Fig. 17. Propuesta 2 - Plano actualizado. Fuente: Los autores. 


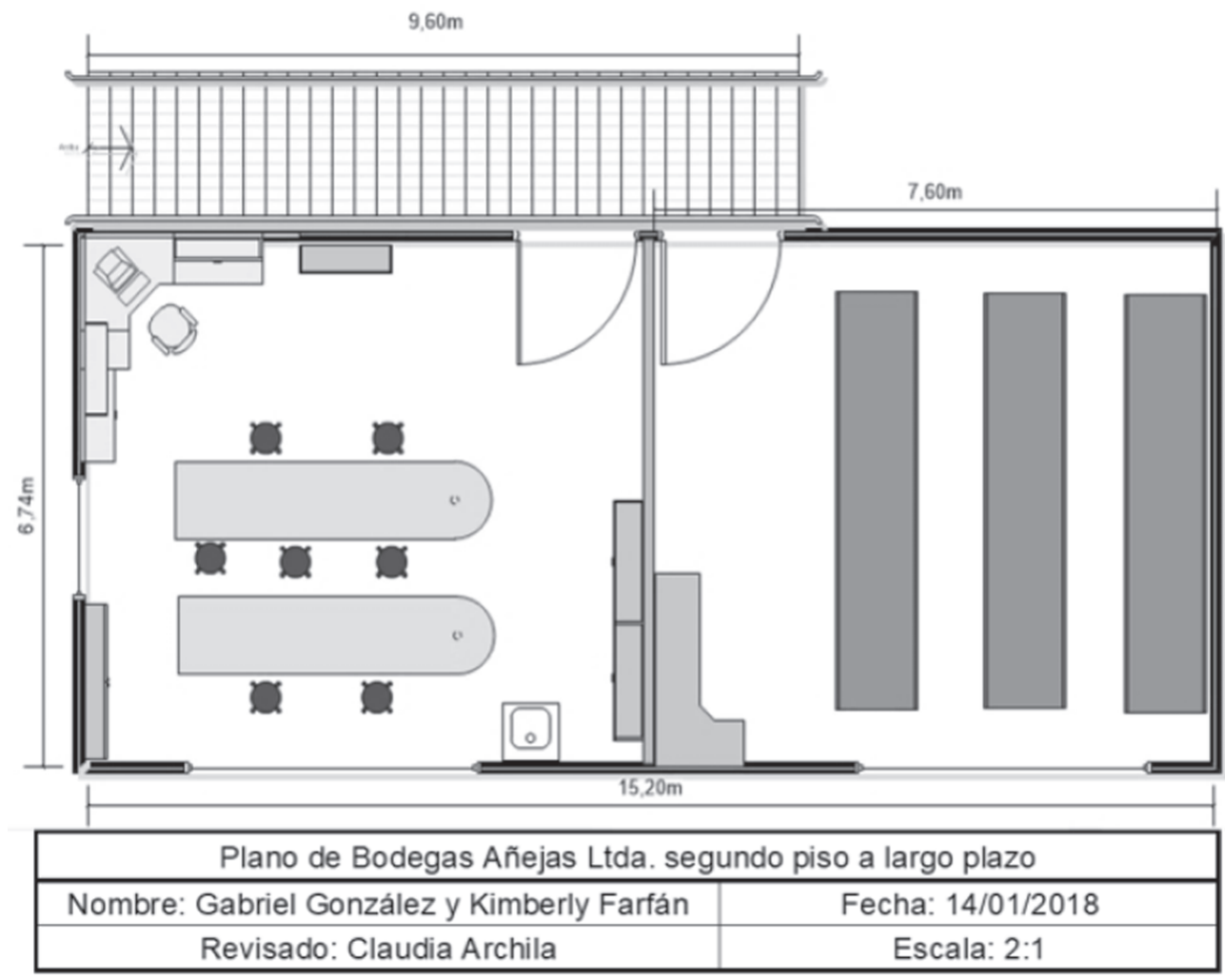

Fig. 18. Propuesta 2 - Plano actualizado segundo piso. Fuente: Los autores.
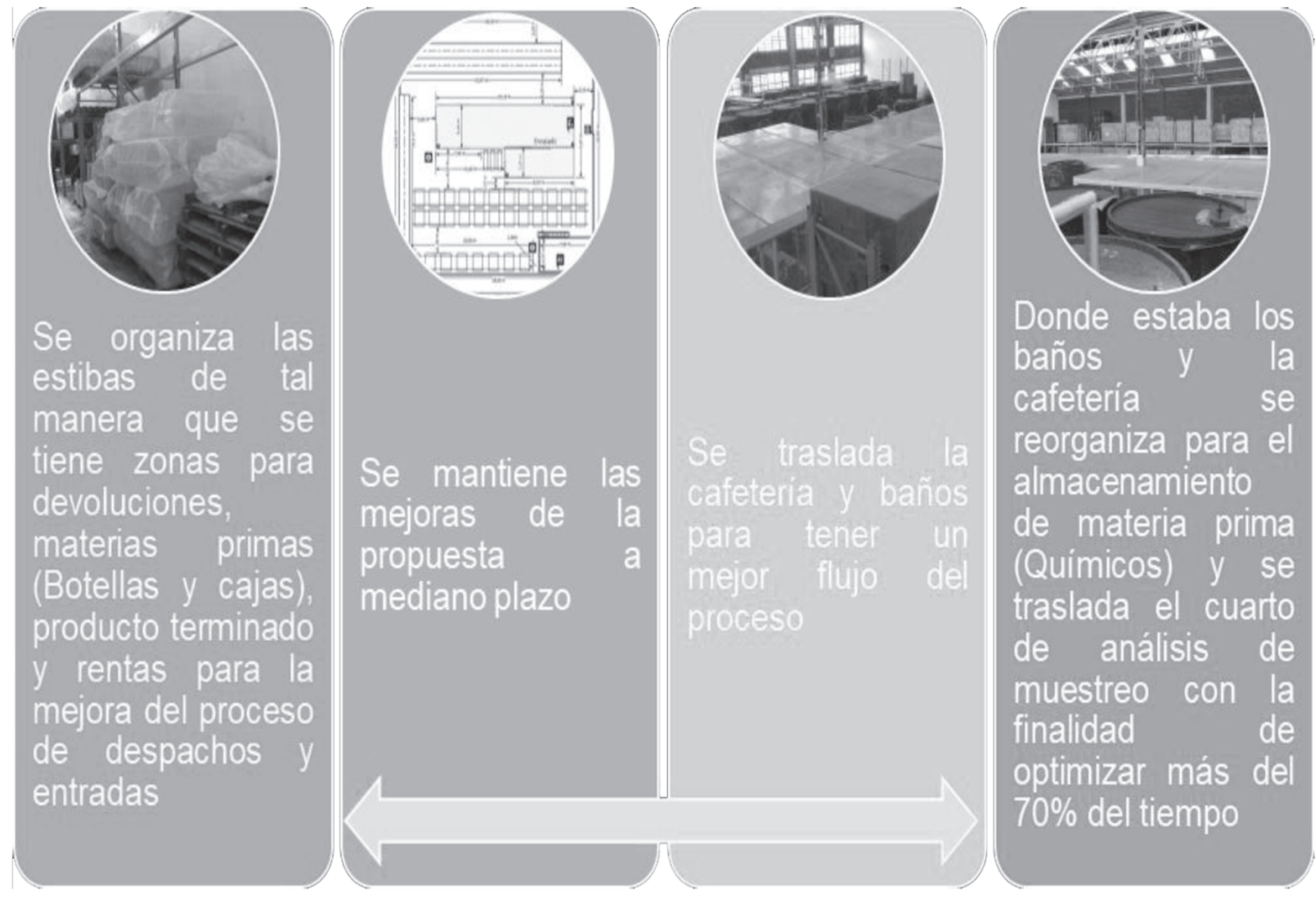

Fig. 19. Beneficios a largo plazo para Bodegas Añejas Ltda. Fuente: Los autores. 
es una técnica experimental para analizar el comportamiento de cualquier sistema operativo del mundo real, involucrando el modelado de un proceso donde esté produce la respuesta del método actual a eventos que ocurren en un período de tiempo determinado [29].

La simulación proyecta unos resultados que permite realizar un análisis de costo beneficio para la empresa, en este proceso se establecieron locaciones de acuerdo al layout, se crea un source para generar los diferentes flow ítems que en este caso es la entrada de materia prima como lo es uvas y químicos, por otra parte se ubica 2 queue que hacen el proceso de producción y producto terminado, además se ubica 3 processor que hace todo el proceso de filtración, clarificación y fermentación, se incorpora 1 multiprocessor que tiene como finalidad la parte de embotellamiento, se ubica 2 racks con 9 columnas de 3 niveles y 1 rack de 10 columnas de 3 niveles, estos racks representan el área de materia prima y producto terminado, para el manejo de productos terminados se maneja un montacarguista que hace el proceso de traslado de materias y 4 personas como auxiliares de bodega.

Al comparar los resultados del proyecto de largo plazo con la bodega actual se tiene un creci- miento en el producto terminó de 21.014 a 22.250 botellas, en temas monetarios la botella tiene un promedio de $\$ 8.000$ y se produjeron 2.108 vinos de más, se tiene una ganancia alrededor de los \$17.000.000. (Ver Tabla XI)

Para concluir, se desarrolla el sistema de gestión de almacenamiento propuesto para Bodegas Añejas Ltda. (Ver Fig. 20) con el propósito de socializar a las personas autorizadas que siguen el control y mejoramiento del sistema, ahorrando tiempo en gestión de procesos e incrementando la capacidad de la organización al momento de realizar sus actividades diarias.

La metodología utilizada en el anterior apartado para el desarrollo de un sistema de gestión de almacenamiento es diferente, puesto que no se han encontrado estudios previos específicos sobre este tema, sin embargo, existen proyectos, artículos y documentos similares publicados sobre sistema de gestión de inventario, gestión de almacén, rediseño de planta; tal es el caso del artículo titulado Mejora del sistema de gestión del almacén de suministros de una empresa productora de gases de uso medicinal e industrial [30]; para el análisis del aporte del proceso realizado, se hace una comparación de la metodología utilizada en el artículo (Ver Tabla XII).

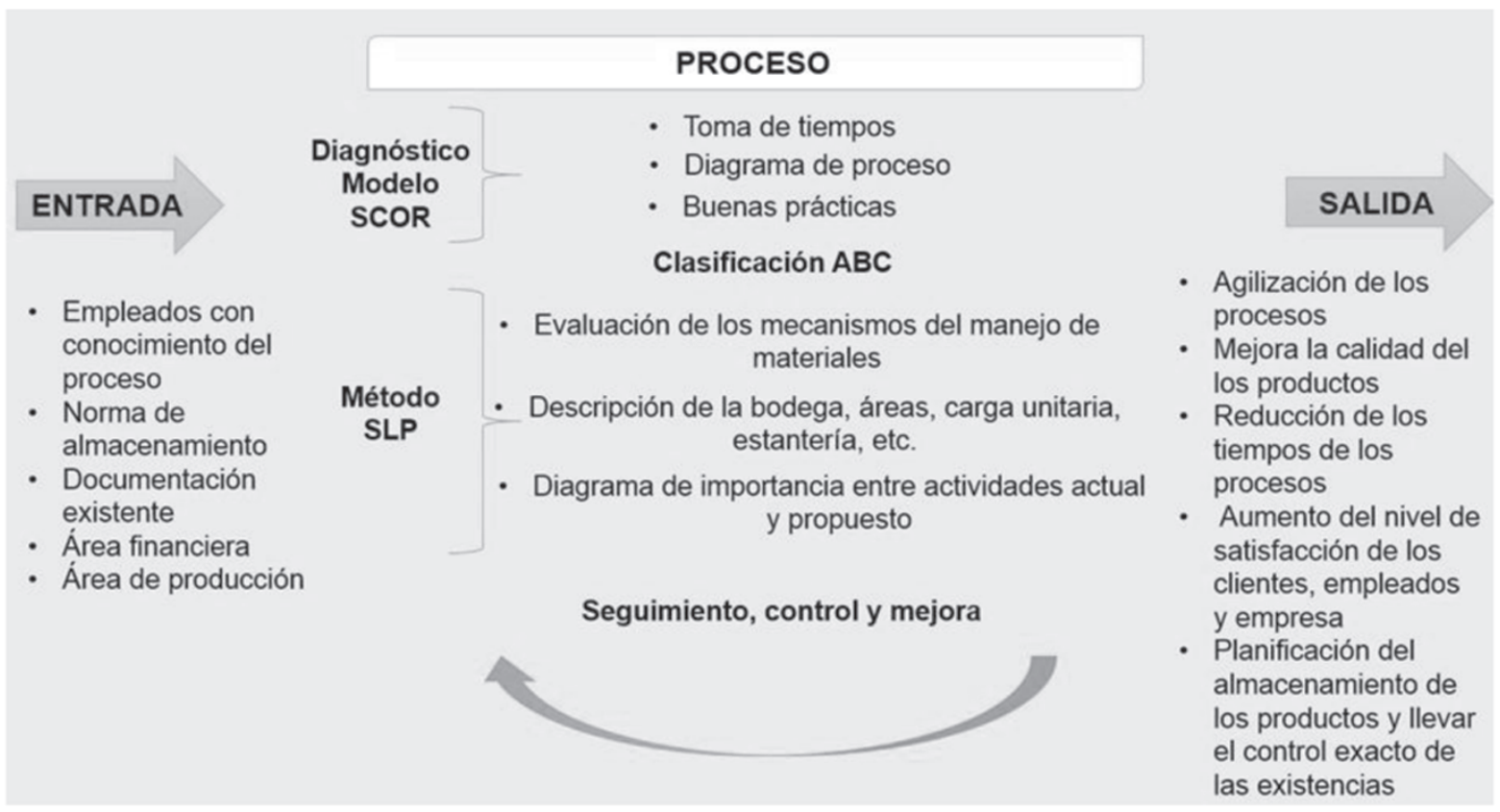

Fig. 20. Sistema de gestión de almacenamiento. Fuente: Los autores. 
Tabla XI. Conclusión de la simulación

\section{SIMULACIONES DE BODEGAS AÑEJAS LTDA.} Simulación

- Actual: El primer processor muestra que tiene un tiempo mínimo de 0.052 segundos para ser utilizado en las actividades de descarga de materia prima, inspección y transporte a la zona de producción, para el segundo processor tiene un tiempo promedio de 25.703 segundos que tiene como referencia la fermentación y el proceso de análisis y para el último processor su tiempo mínimo es de 4.382 segundos que es parte de la filtración y paso a la máquina de multiproceso, que tiene un tiempo mínimo de 0.03 segundos y un máximo de 260.82 segundos que hace referencia a todo el proceso de embotellamiento y terminación del proceso del vino, su source llega a producir 21014 botellas y el área de almacenamiento siempre tiene un stock de 20 estibas y su despacho se hace cada 3 o 5 días.

- Mediano plazo: Para la simulación a mediano plazo se implementa los nuevos almacenamientos para la materia prima (Cajas y botellas), se tiene un sitio específico para la motobomba y se organiza el almacenamiento de los productos terminados, con estas observaciones se puede analizar una mejora de los tiempos del proceso de elaboración del vino, para el nuevo rediseño de la bodega se encontró que el primer processor tiene un tiempo de 0.052 segundos, para el segundo processor su tiempo promedio es de 25 segundos menor al del proceso actual y el tercer processor tiene un mínimo de 4.1 segundos y se incrementa un $0.06 \%$ para la entrada y salida de la materia prima en estos procesos, un source produce 21.812 botellas y el multiproceso con el área de almacenamiento sigue con los mismos tiempos actuales de la bodega.

- Largo plazo: Para esta simulación se mantiene la implementación del almacén y la organización de los materiales que fueron propuestos a mediano plazo y se implementa un nuevo puesto de análisis de muestreo y almacenamiento químico dentro de la zona de producción, la bodega tiene un aumento del producto terminado en $1 \%$ que significa un source de 22250 botellas, el primer processor su tiempo es de 0.042 segundos, para el segundo processor también mejora su tiempo estándar con 23.94 segundos y para el tercer processor tiene un significativo avance con un tiempo mínimo de 3.12 segundos y un tiempo máximo de 261.59 segundos, en el área de multiproceso y el área de almacenamiento sigue con los mismos tiempos actuales de la bodega.
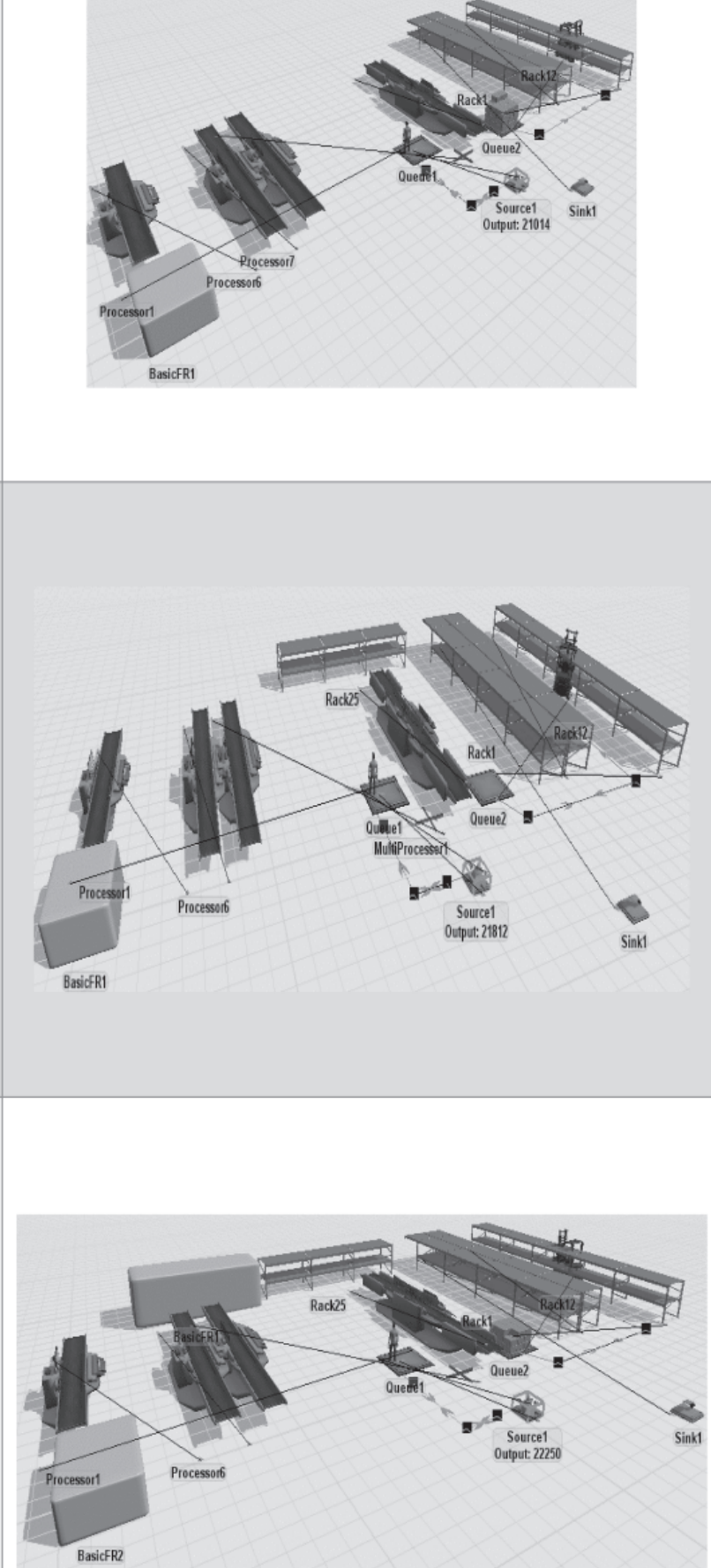

Fuente: Los autores. 
Tabla XII. Cuadro comparativo de metodologías.

\begin{tabular}{|c|c|c|}
\hline & $\begin{array}{l}\text { Desarrollo de un Sistema de gestión de } \\
\text { almacenamiento en Bodegas Añejas Ltda. }\end{array}$ & $\begin{array}{l}\text { Mejora del sistema de gestión del almacén de } \\
\text { suministros de una empresa productora de gases } \\
\text { de uso medicinal e industrial }\end{array}$ \\
\hline Objetivo & $\begin{array}{l}\text { Desarrollar un sistema de gestión de almacén en } \\
\text { BODEGAS AÑJAS LTDA., para el mejoramiento } \\
\text { del control y sistematización de su cadena de } \\
\text { suministro }\end{array}$ & $\begin{array}{l}\text { Proponer mejoras para el sistema de gestión del } \\
\text { almacén de suministros de la empresa Oxígeno } \\
\text { Carabobo, C.A., orientadas a la reducción de los } \\
\text { costos y tiempos de los procesos del almacén }\end{array}$ \\
\hline Palabras claves & $\begin{array}{l}\text { Cadena de suministro, método SCOR, gestión de } \\
\text { almacén, inventario, Flexsim, layout, buenas } \\
\text { prácticas }\end{array}$ & $\begin{array}{l}\text { Mejora, sistema de gestión, almacén, metodología } \\
\text { SHA }\end{array}$ \\
\hline \multirow{11}{*}{ Metodología } & $\begin{array}{l}\text { Para la recolección de información se realizó } \\
\text { reuniones con la gerencia y jefes de áreas para } \\
\text { solicitar registro escrito o virtual, entrevistas no } \\
\text { estructurales y visitas a la bodega }\end{array}$ & $\begin{array}{l}\text { Para obtener información se realizaron visitas al } \\
\text { almacén, mediciones y entrevistas no } \\
\text { estructuradas al personal }\end{array}$ \\
\hline & $\begin{array}{l}\text { Diagrama de Ishikawa para determinar un } \\
\text { conjunto de causas probables o todos aquellos } \\
\text { posibles factores que llevaron a esta problemática }\end{array}$ & $\begin{array}{l}\text { Análisis Sistemático del Manejo de Materiales } \\
\text { (SHA) considerando el sistema de manejo de } \\
\text { materiales utilizado y la distribución actual de las } \\
\text { áreas }\end{array}$ \\
\hline & $\begin{array}{l}\text { Modelo SCOR se utilizó como herramienta de } \\
\text { diagnóstico y mejora de procesos de cadena de } \\
\text { suministro }\end{array}$ & $\begin{array}{l}\text { Diagrama de causa-efecto para identificar las } \\
\text { posibles causas de los problemas presentes }\end{array}$ \\
\hline & $\begin{array}{l}\text { Estudio de tiempos y movimientos con el fin de } \\
\text { eliminar o reducir los movimientos ineficientes y } \\
\text { acelerar los eficientes }\end{array}$ & $\begin{array}{l}\text { Análisis } \mathrm{ABC} \text { por rotación de los productos para } \\
\text { llevar a cabo una adecuada distribución de } \\
\text { almacenes }\end{array}$ \\
\hline & $\begin{array}{l}\text { Diagrama de flujo identificando claramente y de } \\
\text { manera muy visual tanto el inicio y fin del } \\
\text { proceso, como el sentido en el que se desarrollan } \\
\text { las distintas etapas }\end{array}$ & $\begin{array}{l}\text { Diagramas de flujo de las operaciones conocidas } \\
\text { las características generales del almacén y sus } \\
\text { procesos }\end{array}$ \\
\hline & $\begin{array}{l}\text { Diagrama de hilo analizar la trayectoria detallada } \\
\text { del movimiento de material, persona, transporte e } \\
\text { información en el proceso con el fin de mejorar la } \\
\text { ubicación }\end{array}$ & $\begin{array}{l}\text { Técnicas estadísticas y estudios de tiempos } \\
\text { mediante muestreo y cronometrado }\end{array}$ \\
\hline & $\begin{array}{l}\text { Buenas prácticas se generó estrategias para } \\
\text { asegurar un adecuado y eficiente almacenamiento, } \\
\text { transporte y distribución del proceso de } \\
\text { elaboración de vino. }\end{array}$ & $\begin{array}{l}\text { Diagramas de recorridos para la búsqueda de los } \\
\text { artículos por familia }\end{array}$ \\
\hline & $\begin{array}{l}\text { Clasificación } \mathrm{ABC} \text { ayuda a tomar decisiones y } \\
\text { priorizar los recursos del almacén hacia los } \\
\text { productos que más impacto tienen en el mercado }\end{array}$ & Diagrama de Pareto se priorizaron las causas \\
\hline & $\begin{array}{l}\text { Evaluación de mecanismos de almacenamiento } \\
\text { con una check list permitiendo que se valorar de } \\
\text { manera efectiva, la presencia o ausencia de los } \\
\text { elementos }\end{array}$ & $\begin{array}{l}\text { Estudio beneficio-costo para la determinación de } \\
\text { la factibilidad económica de la implementación de } \\
\text { las propuestas }\end{array}$ \\
\hline & $\begin{array}{l}\text { Método Systematic Layout Planning (SLP) se } \\
\text { utiliza para resolver los problemas de distribución } \\
\text { de planta a partir de procesos cualitativos } \\
\text { satisfaciendo las necesidades de la empresa como } \\
\text { distribución de materiales, análisis recorrido de } \\
\text { productos, análisis de relaciones entre actividades, } \\
\text { planificar puestos de trabajo, determinar } \\
\text { requerimientos del área para el almacenamiento y } \\
\text { rediseño del Lay-out }\end{array}$ & \\
\hline & $\begin{array}{l}\text { Simulación software Flexsim para visualizar para } \\
\text { predecir y evaluar numéricamente las propuestas } \\
\text { realizadas para la bodega y tomar una decisión }\end{array}$ & \\
\hline
\end{tabular}

Fuente: Los autores. 


\section{CONCLUSIÓN}

Con esta investigación se identificó los aspectos más relevantes del desarrollo del sistema de gestión de almacenamiento donde se cambia la metodología de diagnóstico DOFA. a aplicar el modelo SCOR. que determina las desconexiones que se presentan y así proponer variables críticas que alimentan el proceso metódico para la elaboración de las alternativas de solución a la problemática; para el mecanismo de evaluación de manejo de material se realiza un check-list que ayuda a conocer y verificar las herramientas que se utilizan durante el proceso de actividades de la operación para así crear estrategias logísticas, mejora de procesos operativos y aumentar la capacidad.

En el rediseño de layout existen diversos métodos de los cuales se identificó que la mejor alternativa es el método SLP. por lo que reúne todas las demás técnicas, permitiendo con exactitud conocer las necesidades de la empresa; la realización de la viabilidad de los rediseños se evalúa con la herramienta Flexsim la cual muestra un mejor flujo para reconocer y calcular porcentajes de optimización respecto a otros Software.

\section{CONFLicto DE INTERESES}

Los autores declaran no tener ningún conflicto de intereses.

\section{REFERENCIAS}

[1] BODEGAS AÑEJAS. Nosotros. Vinosbodega sanejas [Página Web] 2016. [Citado el 21 junio del 2018]. Disponible en: <https://www.vinos bodegasanejas.com/>

[2] E. Peña y E. Forero, Modelo de simulación del proceso de almacenamiento y distribución en la bodega de la distribuidora de papel de la empresa muebles \& accesorios s.a. para el mejoramiento de su sistema de inventarios. Trabajo de grado ingeniería industrial, Bogotá D.C: Universidad Libre Facultad de ingeniería departamento ingeniería industrial, 2012.

[3] L. González, Diseño de un modelo de almacenamiento y distribución de equipos y materiales en la bodega de Saexploration - sucursal Colombia. Repositorio Institucional UMNG [en línea] 2015 disponible en: <http:// docplayer.es/16921063-
Diseno-de-un-modelo-de-almacenamiento-ydistribucion-de-equipos-y-materiales-en-la-bodega-de-saexploration-sucursal-colombia.html>

[4] L. M. Miranda y A. Villamizar, Propuesta de mejoramiento de la cadena de abastecimiento enfocada en la gestión de inventarios, proceso de almacenamiento y preparación de pedidos en el cedi de Colnotex S.A. Trabajo de grado ingeniería industrial, Bogotá D.C: Pontificia Universidad Javeriana. [En línea] 2013. Disponible en: <https://reposi tory.javeriana.edu.co:8443/bitstream/handle/ 10554/6325/MirandaFernandezLinaMaria2013. pdf? sequence $=1 \&$ is Allowed $=y>$

[5] N. Chaparro, Propuesta de mejoramiento del sistema de abastecimiento y almacenamiento del a empresa PLASTIFERGO. Trabajo de grado ingeniería industrial, Bogotá D.C: Pontificia Universidad Javeriana. [En línea] 2013. Disponible en: <https:/ / repository.javeriana.edu.co/bitstream/handle/ 10554/6308/ChaparroSierraNathalia2013.pdf? sequence $=1>$

[6] F. Huamán y P. Sobrino, Diseño de Sistema de Gestión de Almacén para la mejora del control de la información de la Empresa Vitivinícola Bodega Bailetti Chincha - 2012. Trabajo de grado ingeniería de sistemas, Perú, Chicha: Universidad privada Ada A. Byron. [En línea] 2012. Disponible en: <http:/ /repositorio.autonomadeica.edu.pe/bitstream/ autonomadeica / 50 / 3 / FERN ANDO \% 20 HUAMAN\%20ATUNCAR \% 20\% 20-\%20 DISEN\% 20DE\%20SISTEMA \%20DE\%20GESTION \%20DE \% 20ALMACEN.pdf>

[7] P. González, Costos de inventario. [En línea] slideshare 2013. [Citado el 20 febrero del 2017]. Disponible en: <https:/ / es.slideshare.net/pedro4 gonzalez/costos-de-inventario>

[8] B. Salazar, Gestión de Almacenes. [En línea] logisticayabastecimiento 2015. [Citado el 01 marzo del 2017]. Disponible en: <https://logistica yabastecimiento.jimdo.com/almacenamiento/>

[9] B. Salazar, Gestión de Almacenes. Ingeniería industrial. [En línea] Ingenieriaindustrialonline 2016. [Citado el 28 febrero del 2017]. Disponible en: <https:// www.ingenieriaindustrialonline. $\mathrm{com} /$ herramientas-para-el-ingeniero-industrial/ gesti\%C3\%B3n-de-almacenes/>

[10] UAL. Almacén. En: unidad 7. Universidad América Latina [Biblioteca virtual] 2011 Disponible en: <http://ual.dyndns.org/Biblioteca/Compras/ Pdf/Unidad_07.pdf>

[11] REVISTA LOGÍSTICA. Tipos de almacenamiento [En línea] Revista de logística 2016. [Citado el 28 febrero del 2017]. Disponible en: <https:// revistadelogistica.com/almacenamiento/tipos-dealmacenamiento/>

Rev. Ingeniería, Matemáticas y Ciencias de la Información Vol. 6 / Núm. 11 / enero - junio de 2019; pág. 45-71 
[12] REVISTA ZONA LOGÍSTICA. Sistema de almacenamiento en bloque [En línea] Zonalogistica 2017. [Citado el 21 junio del 2018]. Disponible en: <https:// www.zonalogistica.com/sistema-de-almacenamiento-en-bloque/>

[13] L. Manene, Logística, transporte, almacenaje y manutención. [En línea] Luismiguelmanene 2012. [Citado el 28 febrero del 2017]. Disponible en: <http:/ / www.luismiguelmanene.com/2012/06/21/ logistica-transporte-almacenaje-y-manutencion/ >

[14] Noega. Tipos de almacenes en la cadena logística. [En línea] Noega Systems 2016. [Citado el 28 febrero del 2017]. Disponible en: <https:/ / www.noega systems.com/blog/noticias/tipos-de-almacenescadena-logistica>

[15] S. Echevarria, Almacenamiento en estanterías. [En línea] slideshare 2015. [Citado el 28 febrero del 2017]. Disponible en: <https:/ / es.slideshare.net/ SandraEj/almacenamiento-en-estanterias>

[16] J. Espitia, Estantería. [En línea] conocimientos sobrmercadeo 2010. [Citado el 28 febrero del 2017]. Disponible en: <http://conocimientossobre mercadeo.blogspot.com.co/2010/06/estanteria. html>

[17] A. Cruz y E. Ulloa, Optimización de la cadena de distribución del conglomerado pymes del sector cárnico de Bogotá, D.C - gestión de almacenes. [En línea] revista ingeniería, matemáticas y ciencias de la información 2016. [Citado el 01 marzo del 2017]. Disponible en: http:/ /ojs.urepublicana.edu.co/ index.php/ingenieria/article/view/321

[18] B. López, Sistema de Almacenamiento. [En línea] ingenieriaindustrialonline 2016. [Citado el 01 marzo del 2017]. Disponible en: https://www. ingenieriaindustrialonline.com/herramientaspara-el-ingeniero-industrial/gesti $\% \mathrm{C} 3 \% \mathrm{~B} 3 n$-dealmacenes/sistemas-de-almacenamiento/

[19] J. Rodríguez, Sistemas de Almacenamiento. [En línea] prezi.com 2015. [Citado el 01 marzo del 2017]. Disponible en: <https://prezi.com/bybyo8 keudoc/sistemas-de-almacenamiento/>

[20] M. J. Escudero, 5.6. etiquetado y codificación. En: Logística de almacenamiento. Madrid, España: Ediciones Paraninfo SA, 2014. p. 160.

[21] E. De Blas, et al. Codificación de materiales. [En línea] Procesosdealmacn.blogs 2011. [Citado el 28 febrero del 2017]. Disponible en: <http:/ / procesos dealmacn.blogspot.com.co/2011/04/codificacion-de-materiales.html>

[22] E. Martínez; L. Burgeño y J. Castelo. 4.4 Sistemas Informáticos de Administración de Inventarios. Administración de operaciones ITT 2016 [En línea] Sites 2016. [Citado el 28 febrero del 2017].
Disponible en: <https://sites.google.com/site/ clasead m2016/course-feedback/4-4-sistemasinformaticos-de-administracion-de-inventarios>

[23] K. Villegas, Flujos de información y comunicación en logística. [En línea] mailxmail 2006. [Citado el 01 marzo del 2017]. Disponible en: http:// www.mailxmail.com/curso-concepto-logistica/ flujos-informacion-comunicacion-logistica

[24] H. Salazar y C. López, Propuesta metodológica para la aplicación del modelo Supply Chain Operations Reference [En línea] Revista ingeniería, universidad distrital francisco José de Caldas 2009. Disponible en: <http://revistas.udistrital.edu.co/ojs/ index.php/reving/article/download/2377/ 3257>

[25] S. Prakash; Sandeep; G. Soni, Gunjan y Rathore. Supply chain operations reference (scor) model: an overview and a structured literature review of its application [En línea] International Conference on Smart Technologies for Mechanical Engineering, 2013. [Citado el 20 de agosto del 2018]. Disponible en: <https://www.researchgate.net/publication/ 272785183_SUPPLY_CHAIN_OPERATIONS_ REFERENCE_SCOR_MODEL_AN_OVERVIEW_ AND_A_STRUCTURED_LITERATURE_REVIEW _OF_ITS_APPLICATION $>$

[26] Quintana y Rangel, EL DISEÑO DEL SISTEMA DE PRODUCCIÓN [En línea] slideplayer 2017. [Citado el 20 de agosto del 2018]. Disponible en: <https:/ /slideplayer.es/slide/159948/>

[27] I. Vásquez, Tipos de estudio. [En línea] monografías 2005. [Citado el 01 de marzo del 2017] Disponible en la Web: https:/ / www.monografias.com/trabajos75/sistema-control-inventario-empresa-inversiones / sistema-control-inventarioempresa-inversiones3.shtml

[28] P. Fernández y P. Díaz, Investigación cuantitativa y cualitativa. [En línea] fisterra 2002. [Citado el 01 de marzo del 2017]. Disponible en: <https:// www.fisterra.com/mbe/investiga/cuanti_cuali/ cuanti_cuali2.pdf >

[29] F. Meyers y M. Stephens, Definición de la simulación en computadora. Diseño de instalaciones de manufactura y manejo de materiales. 3rd ed. Naucalpan de Juárez: Pearson Educación, p.467. 2006.

[30] J. Huguet, Z. Pineda y E. Gómez, Mejora del sistema de gestión del almacén de suministros de una empresa productora de gases de uso medicinal e industrial. Ingeniería Industrial. Actualidad y Nuevas Tendencias [en línea] 2016, Venezuela. [Citado el 13 de febrero de 2018]. Disponible en:<http://www.redalyc.org/articulo.oa?id= 215049679007> ISSN 1856-8327 
